\title{
Morphological effects on IR band profiles
}

\section{Experimental spectroscopic analysis with application to observed spectra of oxygen-rich AGB stars}

\author{
A. Tamanai ${ }^{1}$, H. Mutschke ${ }^{1}$, J. Blum ${ }^{2}$, Th. Posch ${ }^{3}$, C. Koike ${ }^{4}$, and J. W. Ferguson ${ }^{5}$ \\ 1 Astrophysical Institute and University Observatory, Friedrich-Schiller-University Jena, Schillergäßchen 3, 07745 Jena, Germany \\ e-mail: akemi@astro.uni-jena.de \\ 2 Institut für Geophysik und Extraterrestrische Physik, Technische Universität Braunschweig, Mendelssohnstr. 3 , \\ 38106 Braunschweig, Germany \\ 3 Institut für Astronomie, Türkenschanzstrasse 17, 1180 Wien, Austria \\ ${ }^{4}$ Department of Earth and Space Science, Graduate School of Science, Osaka University, 1-1 Machikaneyama, Toyonaka, \\ Osaka 560-0043, Japan \\ 5 Department of Physics, Wichita State University, Wichita KS67260-0032, USA
}

Received 2 January 2009 / Accepted 24 March 2009

\section{ABSTRACT}

\begin{abstract}
Aims. To trace the source of the unique $13,19.5$, and $28 \mu \mathrm{m}$ emission features in the spectra of oxygen-rich circumstellar shells around AGB stars, we have compared dust extinction spectra obtained by aerosol measurements.

Methods. We have measured the extinction spectra for 19 oxide powder samples of eight different types, such as Ti-compounds (TiO, $\left.\mathrm{TiO}_{2}, \mathrm{Ti}_{2} \mathrm{O}_{3}, \mathrm{Ti}_{3} \mathrm{O}_{5}, \mathrm{Al}_{2} \mathrm{TiO}_{5}, \mathrm{CaTiO}_{3}\right), \alpha-, \gamma-, \chi-\delta-\kappa-\mathrm{Al}_{2} \mathrm{O}_{3}$, and $\mathrm{MgAl}_{2} \mathrm{O}_{4}$ in the infrared region (10-50 $\left.\mu \mathrm{m}\right)$ paying special attention to the morphological (size, shape, and agglomeration) effects and the differences in crystal structure.

Results. Anatase $\left(\mathrm{TiO}_{2}\right)$ particles with rounded edges are the possible 13, 19.5 and $28 \mu \mathrm{m}$ band carriers as the main contributor in the spectra of AGB stars, and spherically shaped nano-sized spinel and $\mathrm{Al}_{2} \mathrm{TiO}_{5}$ dust grains are possibly associated with the anatase, enhancing the prominence of the $13 \mu \mathrm{m}$ feature and providing additional features at $28 \mu \mathrm{m}$. The extinction data sets obtained by the aerosol and CsI pellet measurements have been made available for public use at http://elbe.astro.uni-jena.de.
\end{abstract}

Key words. stars: circumstellar matter - stars: AGB and post-AGB - infrared: stars - methods: laboratory - techniques: spectroscopic

\section{Introduction}

Dust grains, which are composed mostly of micron-sized solid particles, are crucial players for the initial stages of star and planet formation. A significant dust production source is in the outflow of asymptotic giant branch (AGB) stars which lose almost $90 \%$ of their total mass during mass loss at the end of their life time (e.g. Sedlmayr 1994; Gail \& Sedlmayr 1999). Dust formation can only occur if the temperature is low enough and the density of condensable molecules is high enough for condensates to be stable against evaporation. Regions with low temperatures usually occur only at a significant distance above the photosphere with densities that are orders of magnitude lower than in the photosphere of stars (Habing \& Olofsson 2004). Notably, observed emission spectra of AGB stars provide information on the physical and chemical properties of dust grains present. Nevertheless, the chemical and mineralogical composition of dust grains in AGB stars are not yet well understood. Depending on temperature and pressure conditions, high temperature condensates (HTCs) such as corundum, spinel and perovskite (e.g. Grossman \& Larimer 1974; Sharp \& Huebner 1990) are most important because they contribute significant opacity when no other grains are present, even though they are not as abundant as the silicate or iron grains which form at lower temperatures. Once the more abundant grains begin to condense, these less abundant grains lose their significance. Although they are significant only over a narrow range of temperatures, it is an important transition region between the molecular regime and the dust regime (Ferguson et al. 2005).

The strong and unique 13 and $19.5 \mu \mathrm{m}$ emission features detected from oxygen-rich (O-rich) circumstellar envelopes around evolved stars may conceivably be caused by HTCs.

A crystalline form of $\mathrm{Al}_{2} \mathrm{O}_{3}$ has been considered as a carrier of the $13 \mu \mathrm{m}$ feature (e.g. Onaka et al. 1989; Glaccum 1995; Begemann et al. 1997; Sloan et al. 2003; Stroud et al. 2004; DePew et al. 2006). Begemann et al. (1997) demonstrated that amorphous $\mathrm{Al}_{2} \mathrm{O}_{3}$, which was fabricated by a sol-gel technique, is not able to explain the $13 \mu \mathrm{m}$ feature of circumstellar O-rich envelopes. However, they suggested that crystalline $\alpha-\mathrm{Al}_{2} \mathrm{O}_{3}$ may be the $13 \mu \mathrm{m}$ band carrier if the particle shape is taken into consideration. Silicate dust grains might be closely related to the $13 \mu \mathrm{m}$ band as well. Sloan et al. (2003) investigated the correlated dust features at 13,20, and $28 \mu \mathrm{m}$ of O-rich circumstellar shells and suggested that crystalline $\mathrm{Al}_{2} \mathrm{O}_{3}$ is the $13 \mu \mathrm{m}$ feature carrier rather than spinel, and that the 20 and $28 \mu \mathrm{m}$ features are contributed by silicates. Stroud et al. (2004) also proposed that crystalline corundum seems to be a promising candidate for the $13 \mu \mathrm{m}$ feature due to the structure and composition of two formes presolar $\mathrm{Al}_{2} \mathrm{O}_{3}$ grains which were discovered in the Tieschitz ordinary chondrite. These structural and compositional differences are directly linked to the condensation sequence of 
dust grains and reflect the observed spectra. There is absence of the $22 \mu \mathrm{m}$ feature from crystalline corundum in observed spectra as well. DePew et al. (2006) studied the IR spectrum features at 13 and $21 \mu \mathrm{m}$ of AGB stars using the one-dimensional radiative transfer code DUSTY. The target species were corundum, spinel, silicate, and amorphous alumina, and included the effects of grain shape and relative abundances of mixing samples. They found that corundum fit well as the $13 \mu \mathrm{m}$ feature carrier rather than spinel if the grains have a spherical shape.

However, Posch et al. (1999) have shown that neither corundum nor rutile could account for the $13 \mu \mathrm{m}$ emission band because the peak position of corundum was located at slightly shorter wavelength $(12.7 \mu \mathrm{m})$. Only spherical spinel corresponded closely to the $13 \mu \mathrm{m}$ emission band $(12.95 \mu \mathrm{m})$ in their theoretical calculations. Fabian et al. (2001) have examined experimentally the spectra of synthesized spinel by taking different $\mathrm{Al} / \mathrm{Mg}$-ratios into account. They found out that the peak position of the near-stoichiometric synthetic spinel (e.g. $\mathrm{Mg}_{1.01} \mathrm{Al}_{1.99} \mathrm{O}_{4}$ and $\mathrm{Mg}_{0.94} \mathrm{Al}_{2.04} \mathrm{O}_{4}$ ) fit well at $13 \mu \mathrm{m}$ compared with the spectra of O-rich circumstellar shells.

Speck et al. (2000), on the other hand, proposed silicon dioxide $\left(\mathrm{SiO}_{2}\right)$ or polymerized silicates as a $13 \mu \mathrm{m}$ feature carrier candidate. They suggested that the $13 \mu \mathrm{m}$ feature is contributed by the silicates in a similar way to Begemann et al. (1997). Speck et al. (2000) exhibited two polytypes of $\mathrm{SiO}_{2}$ which produced a comparatively clear $13 \mu \mathrm{m}$ band and also pointed out that a detectable amount of $\mathrm{SiO}_{2}$ formation is feasible considering the atomic abundances.

Heterogeneous dust grains have been considered for the identification of the $13 \mu \mathrm{m}$ feature as well. Kozasa \& Sogawa (1997) proposed core-mantle grains which were composed of an $\alpha-\mathrm{Al}_{2} \mathrm{O}_{3}$ core surrounded by a silicate mantle as a possible candidate for the $13 \mu \mathrm{m}$ carrier. Posch et al. (1999) examined the $13 \mu \mathrm{m}$ band profile by making use of the Maxwell-Garnett theory. When the volume fraction of corundum was 0.85 (corundum core $85 \%$ and amorphous olivine mantle $15 \%$ ), the peak position in the spectrum was at $12.95 \mu \mathrm{m}$ in wavelength.

Based upon a model calculation of O-rich circumstellar dust shells around pulsating AGB stars, Jeong et al. (1999) stated that $\mathrm{TiO}_{2}$ would be the most promising candidate as the nucleation seed for further heterogeneous grain growth instead of $\mathrm{Al}_{2} \mathrm{O}_{3}$. Until now, the presence of $\mathrm{TiO}_{2}$ dust grains in spectra of AGB stars has not been confirmed; however, they were identified in meteorites such as carbonaceous chondrites (Greshake et al. 1996, 1998) and the Krymka unequilibrated ordinary chondrites (Nittler et al. 2005). Presolar titanium oxide in unequilibrated ordinary chondrite meteorites has been reported (Nittler et al. 2008). Greshake et al. (1996) suggested that these oxides did not undergo further chemical reactions with remaining nebular gas during the formation of different oxide or silicate dust grains. According to elemental abundances in meteorites (Cameron 1973), magnesium (Mg), silicon ( $\mathrm{Si})$, and iron (Fe) are more abundant than aluminum (Al) and calcium $(\mathrm{Ca})$ by a factor of 12. Titanium (Ti) is a much less abundant metal; it is a factor of 400 times less abundant than Si. Thus Mg-, Si-, Fe-, $\mathrm{Al}-$, and Ca-compounds surpass Ti-compounds in quantity.

Experimentally measured spectra and theoretical calculations which assume simple geometrical models such as spherical (Mie 1908) or ellipsoidal (Bohren \& Huffman 1983) grain shapes have been generally applied to compare models with observed spectra. It has recently become possible to utilize specific methods for particularly inhomogeneous structures and arbitrarily shaped particles for absorption, scattering and extinction calculations (e.g. Purcell \& Pennypacker 1973; Drain 1988;
Mishchenko 1990; Mackowski \& Mishchenko 1996; Min et al. 2005). However, predictions based on these calculations are uncertain since, in reality, grain shape might be tremendously irregular and complex.

Regarding experimental approaches, absorption spectra have been measured by the $\mathrm{KBr}$ (potassium bromide) pellet technique for the mid-IR region in most cases (e.g. Dorschner et al. 1978; Koike et al. 1981; Orofino et al. 1991; Posch et al. 1999; Chihara et al. 2002). A controversial point of this technique is that the band profile is substantially changed by the influence of its electromagnetic polarization since a solid sample is embedded in a medium (KBr) (Fabian et al. 2001).

In this paper, we have experimentally investigated the extinction spectra of $\alpha-, \gamma-, \chi-\delta-\kappa-\mathrm{Al}_{2} \mathrm{O}_{3}, \mathrm{MgAl}_{2} \mathrm{O}_{4}$, and Ticompounds ( $\mathrm{TiO}, \mathrm{TiO}_{2}, \mathrm{Ti}_{2} \mathrm{O}_{3}, \mathrm{Ti}_{3} \mathrm{O}_{5}, \mathrm{Al}_{2} \mathrm{TiO}_{5}, \mathrm{CaTiO}_{3}$ ) in the mid-IR region $(10-50 \mu \mathrm{m})$ to clarify the possible $13,19.5$ and $28 \mu \mathrm{m}$ band carriers with special consideration of morphological effects by the use of the aerosol technique (e.g. Hinds 1999) so as to avoid the influence of electromagnetic interaction with solid embedding media (Tamanai et al. 2006a,b). The aim is to obtain band profiles without the medium effect of these HTCs for a direct comparison to observed spectra and to identify the possible candidates.

\section{Experiment}

\subsection{Classical vs. aerosol techniques}

The pellet technique is the classic technique, where a solid sample is mixed with potassium bromide $(\mathrm{KBr})$, cesium iodide (CsI), or polyethylene (PE) powder that have high transmission through certain IR wavelength ranges, and the mixture is pressed with a 10 Ton load in order to make a $0.55 \mathrm{~mm}$ thick $(1.2 \mathrm{~mm}$ for PE) and $13 \mathrm{~mm}$ diameter pellet for spectroscopic analysis (e.g. Koike \& Hasegawa 1987; Jäger et al. 1994; Begemann et al. 1997; Chihara et al. 2002). The advantages of the pellet technique are low cost, low sample consumption, longevity of the pellets in a desiccator and the exact amount of a measured sample is known. On the other hand, the main disadvantage is that there is the possibility of environmental effects due to the electromagnetic polarization of the embedding medium (e.g. Papoular et al. 1998; Henning \& Mutschke 2000; Speck et al. 2000; Clément et al. 2003). Tamanai et al. (2006a,b) introduced the aerosol technique into dust grain investigation and demonstrated that the strong absorption peaks at approximately 9.8 and $11 \mu \mathrm{m}$ obtained by aerosol measurements for an olivinetype crystalline powder are shifted to shorter wavelengths by amounts of up to $0.24 \mu \mathrm{m}$ compared with spectra obtained by the $\mathrm{KBr}$ pellet measurements. Conversely, weak features are not affected much by the $\mathrm{KBr}$ medium effect (see more details in Tamanai et al. 2006b).

Figure 1 shows the setup of the apparatus for the aerosol measurement. We have utilized a dust flow generator (Palas RBG1000) to disperse a powdered sample in a nitrogen $\left(\mathrm{N}_{2}\right)$ gas stream. The dense aerosol is carried to a two-stage impactor which separates the large particles from the small ones $\left(d_{\text {avg }} \approx 2-3 \mu \mathrm{m}\right)$. The small-grained aerosol are concentrated by the impactor so that a concentration of $10^{6}$ particles per cubic centimeter finally arrives at a White-type long-path infrared cell (MARS-8L/20V, Gemini Scientific Instr.) which has an $18 \mathrm{~m}$ path length by taking advantage of multiple reflections between two gold mirrors mounted on both sides in order to increase the sensitivity. Since a Fourier Transformation Infrared Spectrometer (FTIR, Bruker 113v) with a DTGS detector with 

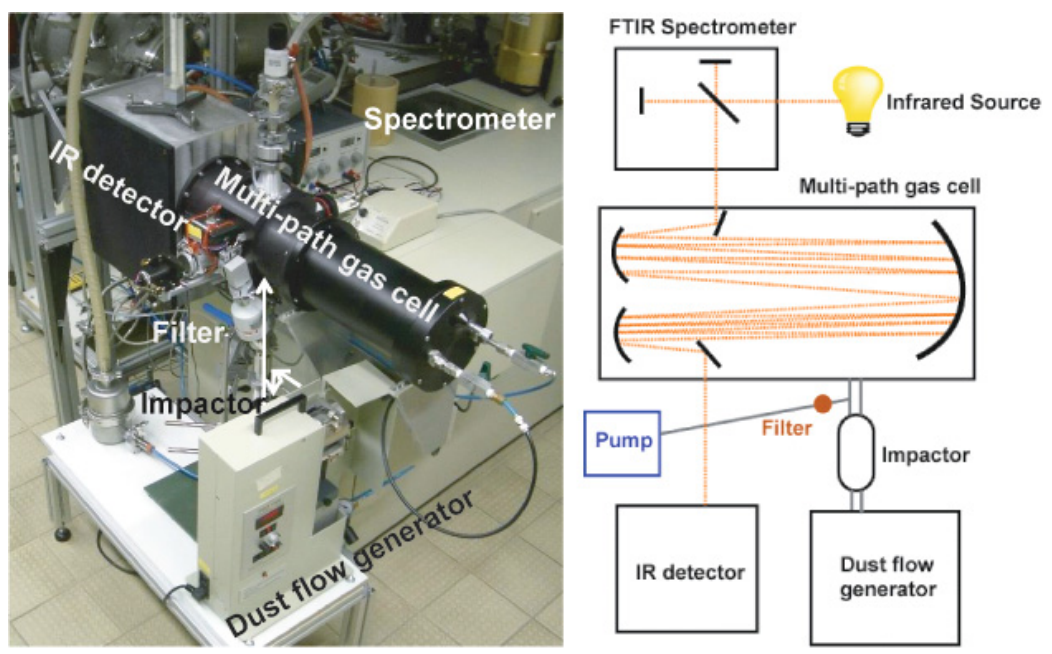

Fig. 1. Experimental apparatus for aerosol extinction measurements. A photo (left) and a schematic diagram (right) of experimental device setup.

CsI windows is fixed to the cell, it is possible to measure the extinction spectrum of the suspended dust particles in $\mathrm{N}_{2}$ gas. As a consequence, we avoid any environmental effect during the aerosol measurement, and the measurement conditions are closer to a vacuum with regard to the dielectric function of the medium $\left(\mathrm{N}_{2}: \epsilon \approx 1.0\right)$ compared to $\mathrm{KBr}(\epsilon=2.3)$. Moreover there is a risk of deforming the powdered sample structure by the high pressure required for the $\mathrm{KBr}$ pellet technique, which is avoided when the aerosol technique is utilized for the measurement.

To make the environmental effect clearer, we have used CsI powder to create pellets as well. CsI is particularly transparent between 2 and $50 \mu \mathrm{m}$ wavelengths, and has a greater optical constant than that of $\mathrm{KBr}(\mathrm{CsI} 1.74 \& \mathrm{KBr} 1.52)$. We have extended the wavelength range up to $50 \mu \mathrm{m}$ for both aerosol and CsI pellet measurements. The aerosol particles are extracted on a polyester-membrane filter which is mounted externally between the outlet of the impactor and the cell. The morphological properties of extracted particles are investigated with a scanning electron microscope (SEM).

\subsection{Samples}

We have investigated 19 powdered crystalline samples of eight different combinations of composition and crystal structure. In particular, for $\mathrm{TiO}_{2}$ and $\mathrm{Al}_{2} \mathrm{O}_{3}$, special attention is paid to the difference in the crystal structures, and $\mathrm{MgAl}_{2} \mathrm{O}_{4}$ and $\mathrm{TiO}_{2}$ are utilized for morphological examination. Table 1 gives a list of the investigated samples including their properties. All the samples are commercial products. Since our aerosol apparatus is highly effective only for particle sizes of less than about $1 \mu \mathrm{m}, \mathrm{Al}_{2} \mathrm{TiO}_{5}$ (original size $\approx 149 \mu \mathrm{m}$ ) and $\mathrm{Ti}_{3} \mathrm{O}_{5}$ (original size $0.1-0.3 \mathrm{~mm}$ ) were milled by a ball mill process $\left(\mathrm{Si}_{3} \mathrm{~N}_{4}\right.$ balls for $30 \mathrm{~min}$ ) to obtain particle sizes less than $1 \mu \mathrm{m}$. In addition, a size fraction $<1 \mu \mathrm{m}$ in diameter for $\chi-\delta-\kappa-\mathrm{Al}_{2} \mathrm{O}_{3}$ is concentrated by sedimentation in a solvent (acetone).

Detailed information of each oxide is given in Appendix A.

\subsection{Equation of state}

The equation of state (EOS) of the PHOENIX stellar atmosphere code can calculate the chemical equilibrium (gas and dust in equilibrium) of 40 elements, including the ionization stages, with hundreds of molecular, liquid, and solid species (see details in Allard et al. 2001; Ferguson et al. 2005). Although the
EOS does not provide information on the chemical pathways, it is possible to obtain number fractions of dust species at specific temperature and pressure points. We use the PHOENIX EOS for our spectroscopic investigation since it can predict the abundance patterns of various dust species in the outflow of AGB stars. Figure 2 shows the abundances of condensates as a function of temperature for a single gas pressure, $10^{4} \mathrm{dyne} / \mathrm{cm}^{2}$. The first dust species to condense are four different crystal structures of $\mathrm{Al}_{2} \mathrm{O}_{3}$ at approximately $1800 \mathrm{~K}$. The most abundant one is $\alpha-\mathrm{Al}_{2} \mathrm{O}_{3}$ followed by $\gamma-, \kappa^{-}, \delta-\mathrm{Al}_{2} \mathrm{O}_{3}$. Then, perovskite appears at around $1700 \mathrm{~K}$. Solid Ti-compounds such as $\mathrm{Ti}_{2} \mathrm{O}_{3}$ and $\mathrm{TiO}_{2}$ come out of the gas phase below $1600 \mathrm{~K}$. $\mathrm{TiO}_{2}$ appears below $1000 \mathrm{~K}$. However, Ti-compounds are less abundant than silicates by a factor of 1000 because $\mathrm{Ti}$ is a factor of 400 less abundant metal than Si (Cameron 1973). The most abundant species above $1500 \mathrm{~K}$ is spinel which appears at about $1600 \mathrm{~K}$ in this calculation. Mg-rich silicate grains dominate below $1500 \mathrm{~K}$ (Note: We plotted only 12 species that have been investigated in our experiments here).

We concentrate on those $\mathrm{HTCs}\left(\mathrm{Al}_{2} \mathrm{O}_{3}\right.$, spinel, and Ticompounds) for experimental spectroscopic analysis (Note: We call HTCs in this paper those species for which dust grains condense out of the gas phase above $1500 \mathrm{~K}$ in this EOS calculation, plus $\mathrm{TiO}_{2}$ ).

\section{Spectroscopic results}

\subsection{Aerosol versus Csl pellet spectra}

The aerosol spectra reveal substantially different band profiles in comparison with the CsI pellet measurements. Tamanai et al. (2006b) demonstrated the disparity between aerosol and $\mathrm{KBr}$ pellet spectra of various silicate samples. Figure 3 shows the three extinction spectra of rutile (CR1) up to $25 \mu \mathrm{m}$ obtained by aerosol, CsI, and $\mathrm{KBr}$ pellet measurements. The strongest peak at $13.53 \mu \mathrm{m}$ of the aerosol spectrum shifts to $15.61 \mu \mathrm{m}$ in wavelength with the CsI pellet measurement $(\Delta \lambda=2.08 \mu \mathrm{m})$. The shift is larger than in the case of the $\mathrm{KBr}$ spectrum which is explained by the relationship between the dielectric functions of a sample $(\epsilon)$ and the embedding medium $\left(\epsilon_{\mathrm{m}}\right)$ (see Bohren \& Huffman 1983). As the value of $\epsilon_{\mathrm{m}}$ increases $\left(\mathrm{N}_{2} 1.0 ; \mathrm{KBr} 2.3\right.$; CsI 3.0), the peak positions are significantly shifted to longer wavelengths by the influence of its electromagnetic polarization.

Figure 4 shows the extinction spectra in the wavelength range between 10 and $50 \mu \mathrm{m}$ for all 19 samples which are 
Table 1. Properties of the samples.

\begin{tabular}{|c|c|c|c|c|c|c|}
\hline Chem. formula & Mineralogical name & Product Info. & Abbr. & Size $(\mu \mathrm{m})$ & Shape & Sect. \\
\hline $\mathrm{TiO}$ & Titanium monoxide & Aldrich & $\mathrm{TiO}$ & $0.1-2.0$ & irr. w/sharp edges & A.1. \\
\hline$\alpha-\mathrm{TiO}_{2}$ & Rutile & Aldrich & $\overline{\mathrm{CR} 1}$ & $0.1-0.5$ & irr. w/round. edges & A.2. \\
\hline$\alpha-\mathrm{TiO}_{2}$ & Rutile & Alfa Aesar & CR2 & $0.1-0.5$ & irr. w/sharp \& round. edges & A. 2 . \\
\hline$\alpha-\mathrm{TiO}_{2}$ & Rutile & Tayca 150W & CR3 & $0.01-0.08$ & thin \& long & A. 2 . \\
\hline$\alpha-\mathrm{TiO}_{2}$ & Rutile & Chitan Inc. No.101 & CR4 & $0.01-0.1$ & sph. \& ellip. & A. 2 . \\
\hline$\beta-\mathrm{TiO}_{2}$ & Anatase & Alfa Aesar & CA1 & $0.1-0.6$ & round. edges & A. 2 . \\
\hline$\beta-\mathrm{TiO}_{2}$ & Anatase & C.P. & CA2 & $0.1-0.2$ & round. \& squ. \& ellip. & A. 2 . \\
\hline$\beta-\mathrm{TiO}_{2}$ & Anatase & Tayca 600 & CA3 & $0.01-0.05$ & round. & A. 2 . \\
\hline$\beta-\mathrm{TiO}_{2}$ & Anatase & Chitan Inc. No.9 & CA4 & $\approx 0.05$ & round. \& long-narrow & A. 2 . \\
\hline $\mathrm{Ti}_{2} \mathrm{O}_{3}$ & Dititanium trioxide & Alfa Aesar & $\mathrm{Ti}_{2} \mathrm{O}_{3}$ & $0.2-1.5$ & irr. w/sharp edges & A.3. \\
\hline $\mathrm{Ti}_{3} \mathrm{O}_{5}$ & Trititanium pentoxide & Alfa Aesar & $\mathrm{Ti}_{3} \mathrm{O}_{5}$ & $0.1-1.0$ & irr. w/sharp edges & A.4. \\
\hline $\mathrm{CaTiO}_{3}$ & Perovskite & Alfa Aesar & $\mathrm{CaTiO}_{3}$ & $0.03-0.5$ & irr. w/sharp edges & A.5. \\
\hline $\mathrm{Al}_{2} \mathrm{TiO}_{5}$ & Tialite & Alfa Aesar & $\overline{\mathrm{Al}_{2} \mathrm{TiO}_{5}}$ & $0.05-0.6$ & irr. w/very sharp edges & A.6. \\
\hline$\alpha-\mathrm{Al}_{2} \mathrm{O}_{3}$ & Corundum & Alfa Aesar & CAC1 & $0.3-0.5$ & irr. w/round. edges & A.7. \\
\hline$\alpha-\mathrm{Al}_{2} \mathrm{O}_{3}$ & Corundum & Glaschemie Jena & CAC2 & $0.06-1.0$ & irr. w/sharp edges & A.7. \\
\hline$\gamma-\mathrm{Al}_{2} \mathrm{O}_{3}$ & & Alfa Aesar & CG & $0.1-0.3$ & squ. w/round. edges & A.7. \\
\hline$\chi-\delta-\kappa-\mathrm{Al}_{2} \mathrm{O}_{3}$ & & C.P. & CCDK & $0.05-1.0$ & irr. \& tabular & A.7. \\
\hline $\mathrm{MgAl}_{2} \mathrm{O}_{4}$ & Spinel & Alfa Aesar & CSp1 & $0.04-0.5$ & irr. w/sharp \& round. edges & A.8. \\
\hline $\mathrm{MgAl}_{2} \mathrm{O}_{4}$ & Spinel & Aldrich & CSp2 & $\approx 0.05$ & sph. & A.8. \\
\hline
\end{tabular}

"C.P." $\rightarrow$ commercial product; "irr." $\rightarrow$ irregular; "round." $\rightarrow$ roundish; "squ." $\rightarrow$ square; "ellip." $\rightarrow$ ellipsoidal; "sph." $\rightarrow$ spherical.

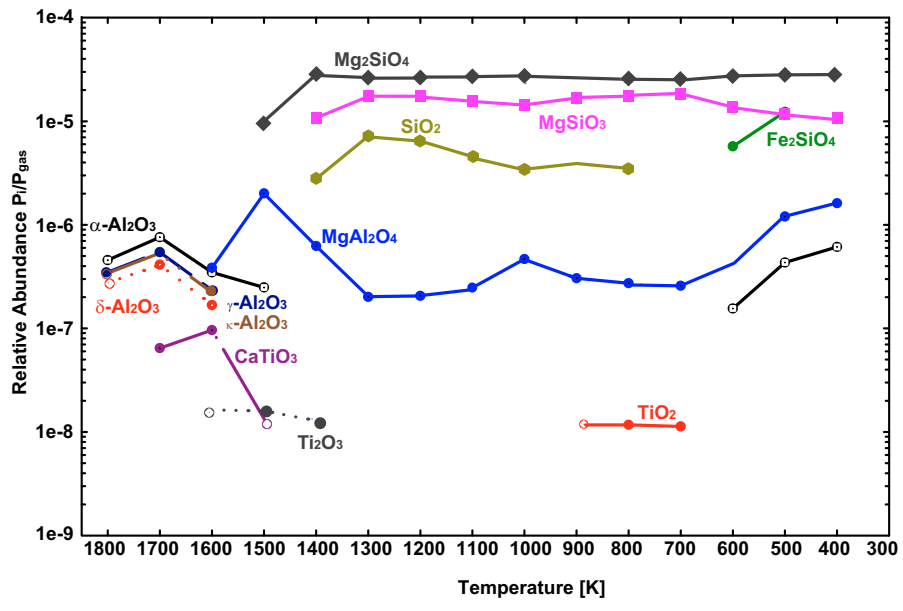

Fig. 2. Relative abundances of dust grain species for a single gas pressure $\left(10^{4} \mathrm{dyne} / \mathrm{cm}^{2}\right)$ as a function of temperature.

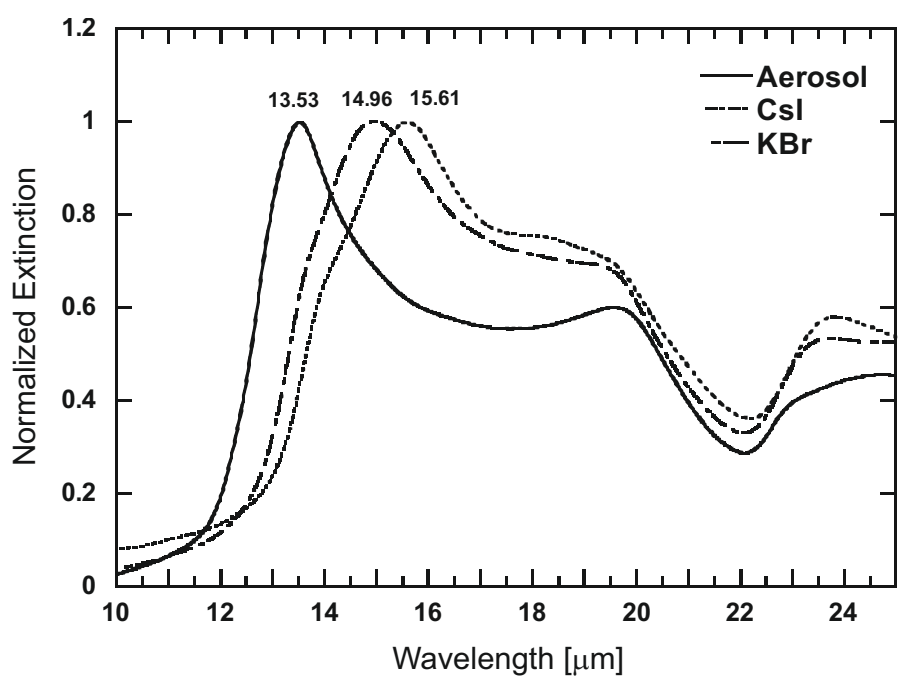

Fig. 3. Normalized extinction vs. wavelength of $\mathrm{TiO}_{2}(\mathrm{CR} 1)$ spectra obtained by aerosol (solid line), CsI (dotted line), and $\mathrm{KBr}$ pellet measurements (dash-dotted line). plotted as normalized extinction (except TiO). The extinction spectra are normalized because aerosol measurements are not quantitative. TiO has a featureless spectrum in both the aerosol and CsI measurements because it is dominated by free charge carrier absorption. The rutile spectra are characterized by a strong, often double-peaked, absorption band between 12 and $22 \mu \mathrm{m}$ (as already shown in Fig. 3), a second absorption band between 22 and $27 \mu \mathrm{m}$, and a third very broad one between 27 and $50 \mu \mathrm{m}$, which is much more centered at the short-wavelength side for the CsI spectra. For one sample (CR3), these three bands are merged into a very broad complex. The strong difference between these spectra and those calculated by Posch et al. (1999) and Posch et al. (2003) for spherical grains will be discussed in the next section. Compared to rutile $\left(\mathrm{TiO}_{2}\right)$, anatase $\left(\mathrm{TiO}_{2}\right)$ lacks the second of the bands and the first one instead extends to somewhat longer wavelengths $(\approx 27 \mu \mathrm{m})$. Also, the $12-27 \mu \mathrm{m}$ band in two cases (CA3 \& CA4) shows strongly pronounced differences between the aerosol and the CsI spectra. While in the first case it is double-peaked, in the second it has only a singlepeaked profile with the peak at 16-18 $\mu \mathrm{m}$. On the other hand, the long-wavelength band has not been observed to be so strongly broadened beyond $40 \mu \mathrm{m}$ as seen for the rutile samples CR1 and CR4.

The calculations for spherical particles presented by Posch et al. (2003) produce a double band peaking at 13 and $15 \mu \mathrm{m}$ and a sharp $27.5 \mu \mathrm{m}$ band. The CA1 and CA2 aerosol spectra come relatively close to this prediction, although the profiles are much broader (see next section). $\mathrm{Ti}_{2} \mathrm{O}_{3}$ has a double-peaked band between 17 and $21 \mu \mathrm{m}$ and only weak features longward of it. The aerosol-measured spectrum reproduces very well the calculated spectrum for spherical particles (Posch et al. 2003). The (normalized) spectrum of CsI embedded particles shows an enhanced far-infrared extinction, which is probably due to conductivity and certainly is enhanced by agglomeration within the pellet (see also the $\mathrm{TiO}$ spectrum). The $\mathrm{Ti}_{3} \mathrm{O}_{5}$ spectrum does not show this effect, but is complicated in terms of the appearance of many peaks. These peaks do not group into clear complexes, unlike the simpler titanium oxides.

Perovskite again has a divided spectrum with a relatively narrow short-wavelength band, the peak of which shifts strongly 

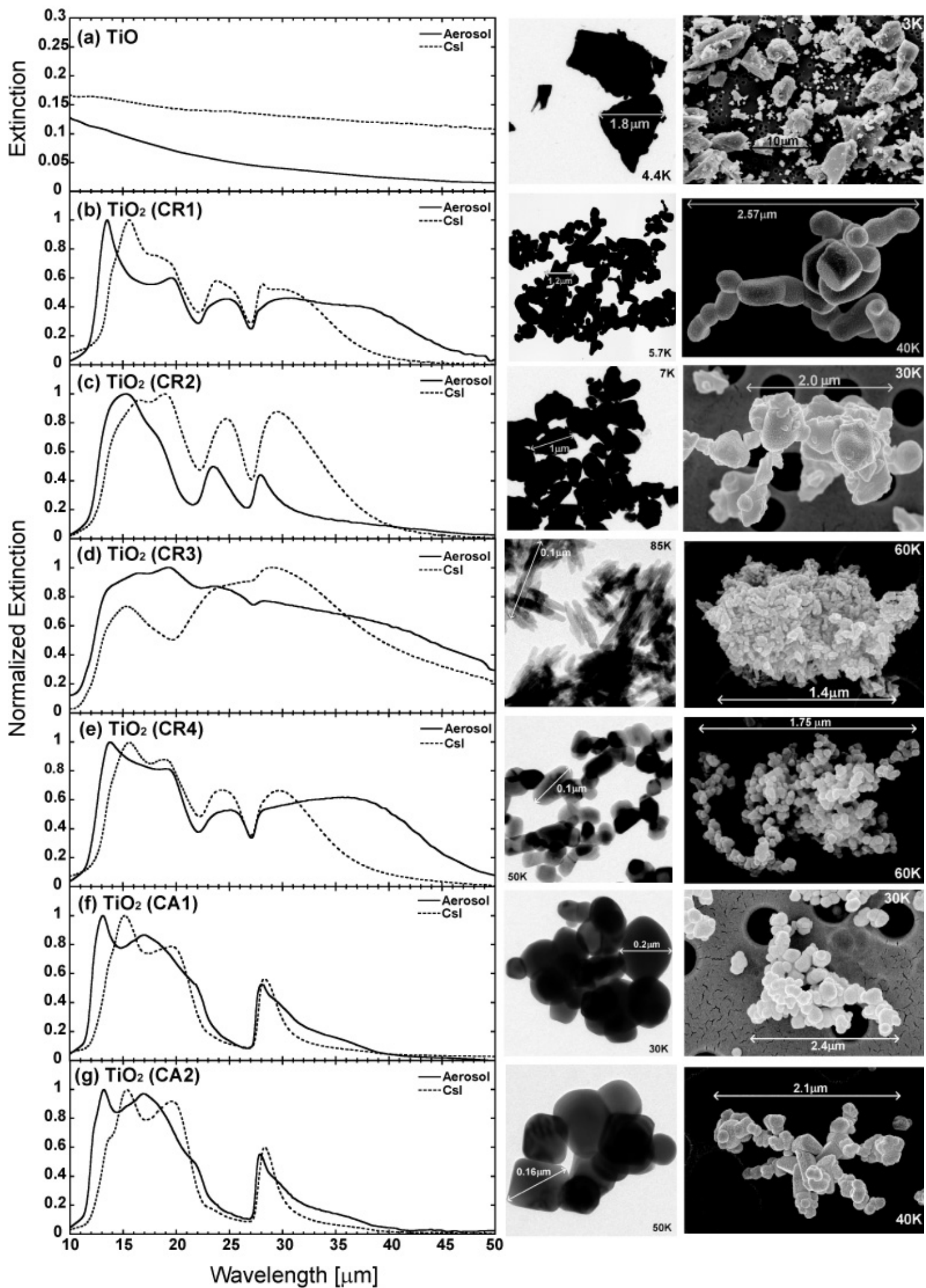

Fig. 4. Left: normalized extinction vs. wavelength of a) $\mathrm{TiO}$; b) $\mathrm{TiO}_{2}(\mathrm{CR} 1)$; c) $\mathrm{TiO}_{2}(\mathrm{CR} 2)$; d) $\mathrm{TiO}_{2}(\mathrm{CR} 3) ;$ e) $\mathrm{TiO}_{2}(\mathrm{CR} 4)$; f) $\mathrm{TiO}{ }_{2}(\mathrm{CA} 1)$; g) $\mathrm{TiO} 2$ (CA2) spectra obtained by aerosol and CsI pellet measurements. Center: TEM images (original powder). Right: SEM images (aerosol particles). Note that only the TiO spectrum is not normalized.

with the embedding medium. Even for the aerosol spectrum, the peak is at longer wavelengths compared to the calculated spectrum for spherical grains presented by Posch et al. (2003), whereas the longer-wavelength bands reproduce the calculated 


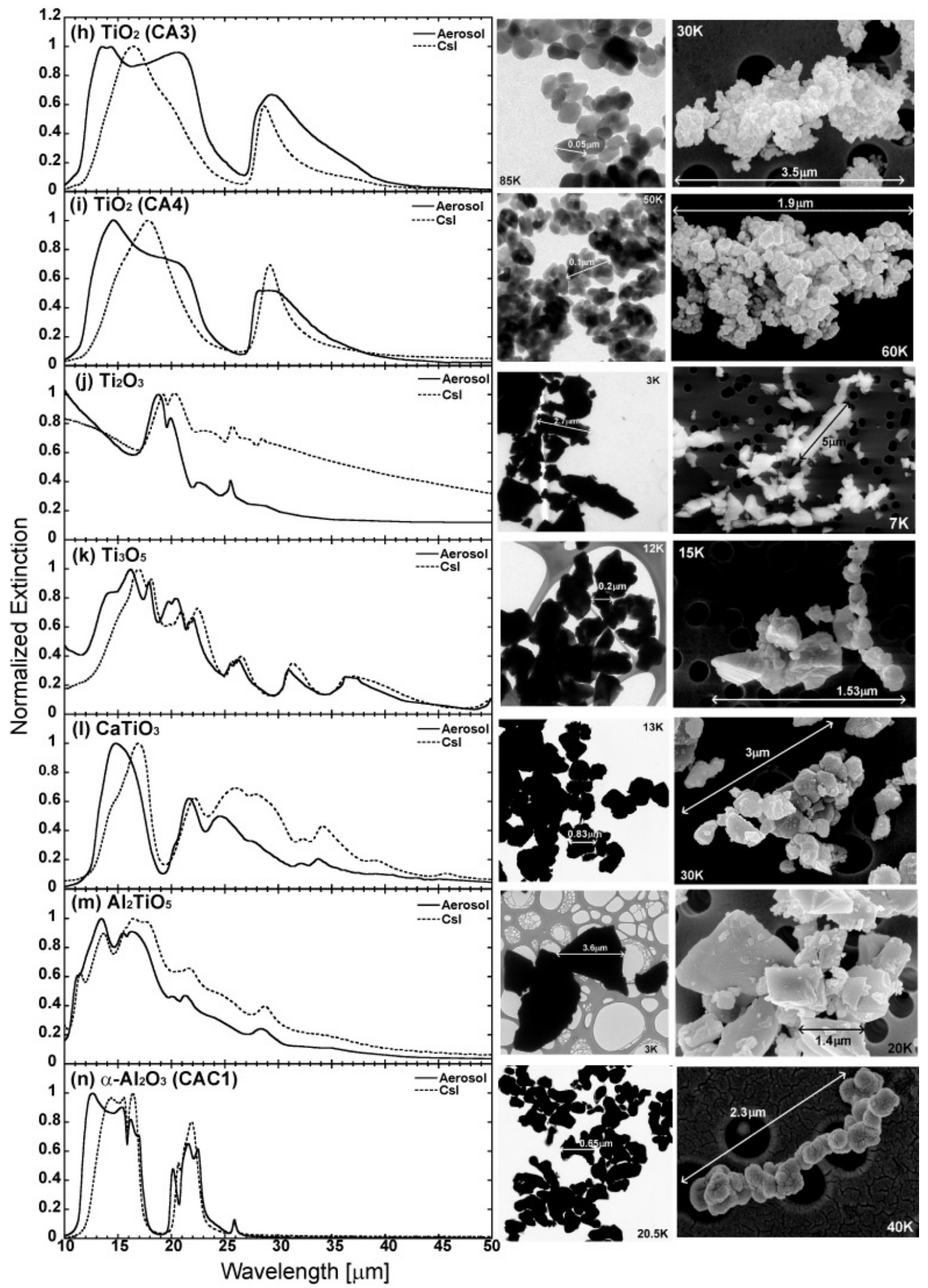

Fig. 4. continued. Left: normalized extinction vs. wavelength of h) $\mathrm{TiO}_{2}(\mathrm{CA} 3)$; i) $\left.\left.\left.\left.\mathrm{TiO}_{2}(\mathrm{CA} 4) ; \mathbf{j}\right) \mathrm{Ti}_{2} \mathrm{O}_{3} ; \mathbf{k}\right) \mathrm{Ti}_{3} \mathrm{O}_{5} ; \mathbf{l}\right) \mathrm{CaTiO}_{3} ; \mathbf{m}\right) \mathrm{Al}_{2} \mathrm{TiO}_{5}$; n) $\alpha-\mathrm{Al}_{2} \mathrm{O}_{3}(\mathrm{CAC} 1)$ spectra obtained by aerosol and CsI pellet measurements. Center: TEM images (original powder). Right: SEM images (aerosol particles).

band positions quite well. The aluminum titanate spectrum lacks this division and is in fact reminiscent of the $\gamma-\mathrm{Al}_{2} \mathrm{O}_{3}$ spectrum with some additional smaller structures, but not as many as the $\chi-\delta-\kappa-\mathrm{Al}_{2} \mathrm{O}_{3}$. 


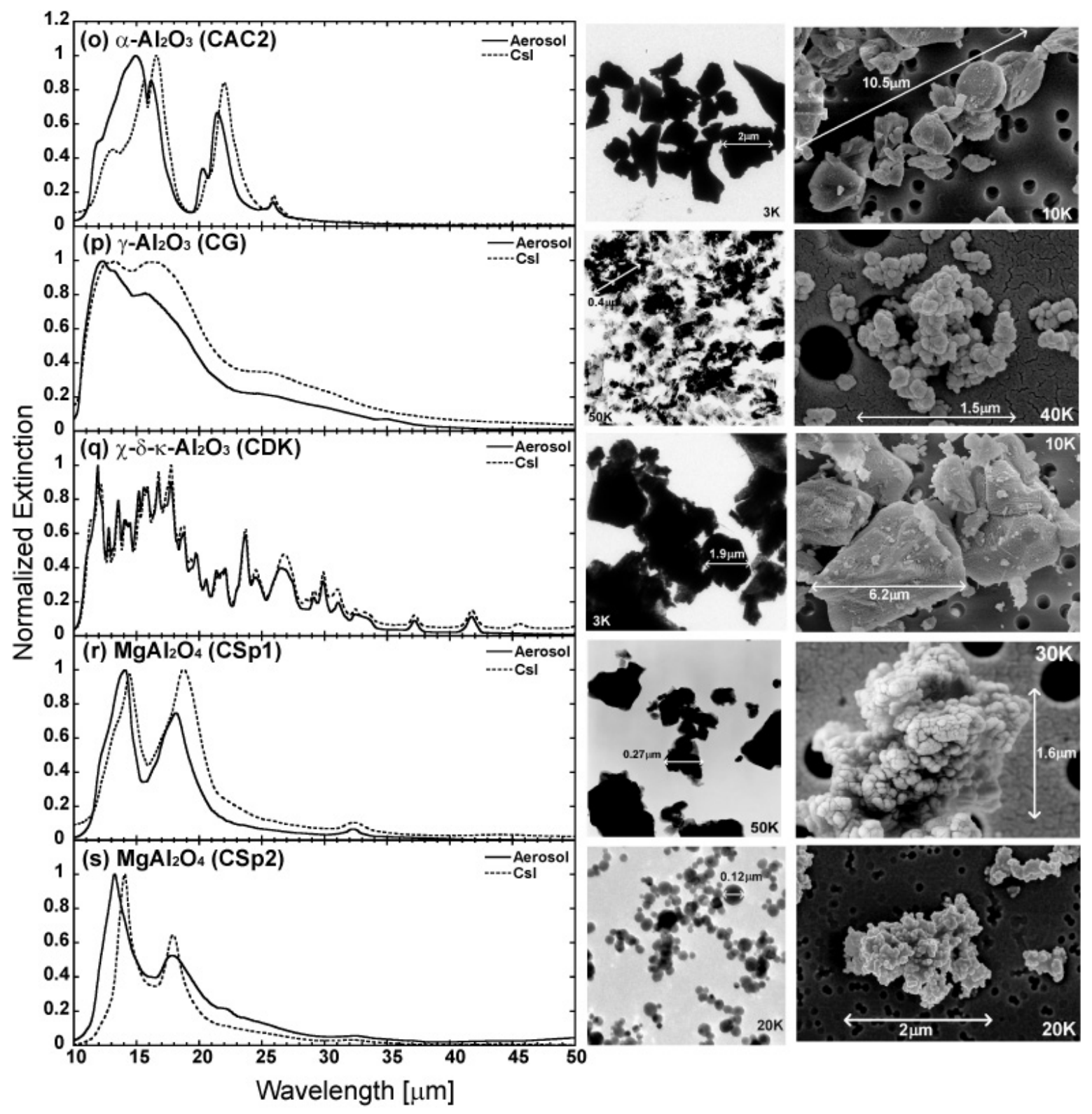

Fig. 4. continued. Left: normalized extinction vs. wavelength of o) $\left.\left.\left.\alpha-\mathrm{Al}_{2} \mathrm{O}_{3}(\mathrm{CAC} 2) ; \mathbf{p}\right) \gamma-\mathrm{Al}_{2} \mathrm{O}_{3}(\mathrm{CG}) ; \mathbf{q}\right) \chi-\delta-\kappa-\mathrm{Al}_{2} \mathrm{O}_{3}(\mathrm{CCDK}) ; \mathbf{r}\right) \mathrm{MgAl} \mathrm{O}_{4}$ (CSp1); s) $\mathrm{MgAl}_{2} \mathrm{O}_{4}$ (CSp2) spectra obtained by aerosol and CsI pellet measurements. Center: TEM images (original powder). Right: SEM images (aerosol particles).

Koike et al. (1995) performed extinction efficiency measurements of two different $\gamma-\mathrm{Al}_{2} \mathrm{O}_{3}$ samples (commercial aerosil particles and a combustion product). Both samples showed a double peak at approximately 12.4 and $13.9 \mu \mathrm{m}$. Similarly, Kurumada et al. (2005) carried out transmittance measurements of commercial $\gamma-\mathrm{Al}_{2} \mathrm{O}_{3}$ particles, and they detected a double peak at about 12.5 and $13.5 \mu \mathrm{m}$ in wavelengths as well. These results fit well with our measurements (aerosol 12.3-13.1 $\mu \mathrm{m}$ \& CsI 12.7-13.6 $\mu \mathrm{m}$ ). Moreover, the aerosil spectrum from Koike et al. (1995) exhibited also a small shoulder around 17$18 \mu \mathrm{m}$. The small shoulder is apparent in our $\gamma-\mathrm{Al}_{2} \mathrm{O}_{3}$ spectra obtained by both the aerosol $(15.7 \mu \mathrm{m})$ and CsI pellet $(16.6 \mu \mathrm{m})$ measurements. The slight differences in peak positions come from mainly two factors. One is the medium effect since all observations utilized different substances as a medium. Koike et al. (1995) and Kurumada et al. (2005) used $\mathrm{KBr}$ powder whereas we applied $\mathrm{N}_{2}$ gas for the aerosol measurements and CsI for the pellet measurements. Another factor is the morphological effect. Our $\gamma-\mathrm{Al}_{2} \mathrm{O}_{3}$ particles are square shape with rounded edges and $0.1-0.3 \mu \mathrm{m}$ in size while the aerosil particles (Koike et al. 1995) were disk shape with a mean diameter of $0.02 \mu \mathrm{m}$.

Corundum shows two strong band complexes at 11-18 and 19-23 $\mu \mathrm{m}$ plus a small band at $26 \mu \mathrm{m}$. Both complexes have clear substructures, although the structure strongly depends on the sample (see below). The spectra do not show dominant sharp peaks at $13 \mu \mathrm{m}$ or shortward of $13 \mu \mathrm{m}$, which would be expected for spherical grains according to Mie calculations (Begemann et al. 1997; Posch et al. 1999).

Another important point for $\mathrm{Al}_{2} \mathrm{O}_{3}$ is the state of its crystal structure. Though it is obvious to confirm the morphological differences among these $\mathrm{Al}_{2} \mathrm{O}_{3}$ samples via the SEM and TEM images, these band profiles are significantly affected by differences in the crystal structures, in this case more than by the morphological effects. 
Table 2. The peak positions $(\mu \mathrm{m})$ for the aerosol and CsI measurements for all samples except TiO.

\begin{tabular}{|c|c|c|c|c|c|c|c|c|c|c|}
\hline Chemical formula & Abbrev. & Measurement & & & & Peaks & {$[\mu \mathrm{m}]$} & & & \\
\hline \multirow{2}{*}{$\mathrm{TiO}_{2}$} & CR1 & Aerosol & 13.53 & 19.56 & 24.70 & 30.30 & 35.80 & & & \\
\hline & & CsI & 15.61 & 23.77 & 28.13 & 29.81 & & & & \\
\hline \multirow[t]{2}{*}{$\mathrm{TiO}_{2}$} & CR2 & Aerosol & 15.33 & 23.50 & 27.95 & & & & & \\
\hline & & CsI & 16.58 & 18.94 & 24.71 & 29.55 & & & & \\
\hline \multirow[t]{2}{*}{$\mathrm{TiO}_{2}$} & CR3 & Aerosol & 16.47 & $\mathbf{1 9 . 2 5}$ & 23.39 & 28.27 & & & & \\
\hline & & CsI & 15.38 & 29.01 & & & & & & \\
\hline \multirow[t]{2}{*}{$\mathrm{TiO}_{2}$} & CR4 & Aerosol & 13.79 & 19.27 & 25.59 & 35.64 & & & & \\
\hline & & CsI & 15.51 & 19.03 & 24.26 & 29.68 & & & & \\
\hline \multirow[t]{2}{*}{$\mathrm{TiO}_{2}$} & CA1 & Aerosol & 13.10 & 16.90 & 28.19 & & & & & \\
\hline & & CsI & 15.20 & 19.60 & 28.26 & & & & & \\
\hline \multirow[t]{2}{*}{$\mathrm{TiO}_{2}$} & CA2 & Aerosol & 13.22 & 16.90 & 27.90 & & & & & \\
\hline & & CsI & 15.34 & 19.56 & 28.30 & & & & & \\
\hline \multirow[t]{2}{*}{$\mathrm{TiO}_{2}$} & CA3 & Aerosol & $\overline{13.46}$ & 14.34 & 20.63 & 29.37 & & & & \\
\hline & & CsI & 16.45 & 28.79 & & & & & & \\
\hline \multirow[t]{2}{*}{$\mathrm{TiO}_{2}$} & CA4 & Aerosol & 14.58 & 19.89 & 28.26 & & & & & \\
\hline & & CsI & 17.78 & 29.19 & & & & & & \\
\hline \multirow[t]{2}{*}{$\mathrm{Ti}_{2} \mathrm{O}_{3}$} & $\mathrm{Ti}_{2} \mathrm{O}_{3}$ & Aerosol & 18.22 & 19.90 & 22.62 & 25.54 & & & & \\
\hline & & CsI & 19.28 & 20.30 & 23.11 & 25.72 & 28.53 & & & \\
\hline \multirow[t]{4}{*}{$\mathrm{Ti}_{3} \mathrm{O}_{5}$} & $\mathrm{Ti}_{3} \mathrm{O}_{5}$ & Aerosol & 16.21 & 17.91 & 19.73 & 20.36 & 21.69 & 22.07 & 25.44 & 26.06 \\
\hline & & & 30.89 & 35.92 & & & & & & \\
\hline & & CsI & 16.89 & 18.14 & 19.87 & 20.93 & 24.44 & 25.64 & 26.57 & 31.37 \\
\hline & & & 37.14 & & & & & & & \\
\hline \multirow{2}{*}{$\mathrm{CaTiO}_{3}$} & $\mathrm{CaTiO}_{3}$ & Aerosol & 14.85 & 21.67 & 24.56 & 32.13 & 33.71 & & & \\
\hline & & CsI & 16.89 & 22.18 & 25.95 & 27.86 & 32.30 & 34.16 & 38.96 & 45.70 \\
\hline \multirow[t]{2}{*}{$\mathrm{Al}_{2} \mathrm{TiO}_{5}$} & $\mathrm{Al}_{2} \mathrm{TiO}_{5}$ & Aerosol & $\overline{13.48}$ & 15.48 & 16.31 & 19.96 & 21.33 & 28.38 & & \\
\hline & & CsI & 9.56 & 11.48 & 13.59 & 16.54 & 20.67 & 21.61 & 28.72 & \\
\hline \multirow[t]{2}{*}{$\alpha-\mathrm{Al}_{2} \mathrm{O}_{3}$} & CAC1 & Aerosol & 12.65 & 15.37 & 16.16 & 16.91 & 20.14 & 21.57 & 22.48 & 25.92 \\
\hline & & CsI & 14.31 & 14.46 & 16.39 & 20.67 & 21.91 & 25.91 & & \\
\hline \multirow[t]{2}{*}{$\alpha-\mathrm{Al}_{2} \mathrm{O}_{3}$} & CAC2 & Aerosol & 14.92 & 16.16 & 20.30 & 21.45 & 25.89 & & & \\
\hline & & CsI & 13.15 & 15.63 & 16.59 & 20.88 & 22.01 & 25.95 & & \\
\hline \multirow[t]{2}{*}{$\gamma-\mathrm{Al}_{2} \mathrm{O}_{3}$} & CG & Aerosol & 12.32 & 13.13 & 15.71 & & & & & \\
\hline & & CsI & 12.69 & 13.60 & 16.02 & 24.06 & & & & \\
\hline \multirow[t]{7}{*}{$\chi-\delta-\kappa-\mathrm{Al}_{2} \mathrm{O}_{3}$} & CDK & Aerosol & 11.93 & 12.79 & 13.56 & 14.08 & 14.47 & 15.19 & 15.87 & 16.76 \\
\hline & & & 17.74 & 18.77 & 19.32 & 19.77 & 20.56 & 21.38 & 22.07 & 23.69 \\
\hline & & & 24.48 & 26.62 & 29.15 & 29.89 & 31.09 & 32.46 & 37.20 & 41.70 \\
\hline & & CsI & 11.45 & 11.93 & 12.19 & 12.81 & 13.57 & 14.07 & 14.26 & 14.52 \\
\hline & & & 15.21 & 15.62 & 15.88 & 16.76 & 17.78 & 18.58 & 19.29 & 19.78 \\
\hline & & & 20.58 & 21.42 & 21.78 & 22.09 & 23.69 & 24.53 & 26.80 & 28.53 \\
\hline & & & 29.15 & 29.90 & 31.06 & 32.48 & 33.19 & 37.18 & 41.75 & 45.53 \\
\hline \multirow[t]{2}{*}{$\mathrm{MgAl}_{2} \mathrm{O}_{4}$} & CSp1 & Aerosol & 14.08 & 18.14 & 32.30 & & & & & \\
\hline & & CsI & 14.45 & 18.80 & 32.34 & & & & & \\
\hline \multirow[t]{2}{*}{$\mathrm{MgAl}_{2} \mathrm{O}_{4}$} & CSp2 & Aerosol & 13.26 & 17.79 & 32.61 & & & & & \\
\hline & & CsI & 14.07 & 17.91 & 32.31 & & & & & \\
\hline
\end{tabular}

Kurumada et al. (2005) produced nano-sized spherical $\delta-\mathrm{Al}_{2} \mathrm{O}_{3}$ particles by the gas evaporation method and measured the transmittance spectra by making use of the KBr pellet technique. They detected 15 absorption peaks in the wavelength range between 10 and $19 \mu \mathrm{m} . \delta-\mathrm{Al}_{2} \mathrm{O}_{3}$ showed many sharp peaks in an exceptionally broad absorption region $(10-20 \mu \mathrm{m})$. A similar result is obtained in our $\chi-\delta-\kappa-\mathrm{Al}_{2} \mathrm{O}_{3}$ sample investigation up to $20 \mu \mathrm{m}$, and more peaks are observed in both the aerosol and CsI pellet spectra up to $46 \mu \mathrm{m}$.

The relation between cubic alumina and (non-stoichiometric) spinel spectra has already been discussed by Fabian et al. (2001) based on reflection spectra. It is interesting to note that the aerosol measurement of $\gamma$-alumina shows a dominance of the $12.5 \mu \mathrm{m}$ peak in the spectrum and a shift of this feature to shorter wavelengths compared to the CsI measurement. The spectrum comes rather close to that calculated by Begemann et al. (1997) for a shape distribution from the optical constants presented by Koike et al. (1995), although an additional shoulder at $15.7 \mu \mathrm{m}$ is seen. This shoulder becomes a strong band in the CsI spectrum.
The spinel spectra show two main bands at about $13-14 \mu \mathrm{m}$ and $17-19 \mu \mathrm{m}$ depending on sample and embedding. The band at $32 \mu \mathrm{m}$ is also clearly seen in both the aerosol and CsI spectra. Based on calculations for spherical grain shapes, Fabian et al. (2001) proposed that synthetic and also annealed natural spinel particles would reproduce the $13 \mu \mathrm{m}$ band of AGB stars. Our samples CSp1 and CSp2 both are synthetic material. The CSp2 spectrum measured in aerosol peaks at $13.26 \mu \mathrm{m}$, but when measured in CsI, the peak is shifted to more than $14 \mu \mathrm{m}$, which is similar to the position reported by Posch et al. (1999) for spinel particles in $\mathrm{KBr}$. The CSp1 spectra peak at more than $14 \mu \mathrm{m}$ in all cases, which will be discussed in the next section.

In general, there is a clear trend that the aerosol spectra have peaks at significantly shorter wavelengths than the CsI spectra. In particular, this is always true for the shortest-wavelength peak. However, as already mentioned for anatase, in most cases the matrix effect cannot be reduced to a simple peak shift. Specifically for strong bands, the band profiles measured in aerosol sometimes show a broadening to longer wavelengths 
as well, sometimes resulting in a secondary peak and a nearrectangular total profile. These effects are seen to a much lesser extent in the CsI spectra. This may partially also be a consequence of differences in the particle morphology, which may have been caused by

(a) using different dispersion methods;

(b) particles may transform during the grinding procedure;

(c) powdered sample structure deformation caused by the high pressurization required for the CsI pellet technique.

A large difference in band profiles between the aerosol and CsI pellet measurements is possibly produced more by spherical and ellipsoidal shapes than irregular ones.

\subsection{Morphological effects}

One of the advantages of using the aerosol technique in the investigation of dust is that it is possible to inspect the particle morphology. We set a polyester-membrane filter between the outlet of the impactor and the cell (Fig. 1) and extract the incoming aerosol particles. These captured aerosol particles are analyzed by a SEM. The SEM images are shown in Fig. 4 (right). A TEM has also been utilized to understand the individual particle shape as well (Fig. 4 middle images).

The spectrum of CR1 (Fig. 4b) shows a similar band profile to that of CR4 in Fig. 4e. Although the particle sizes of these samples are different from each other, there are two major similarities. The individual particle shape is irregular with roundish edges. The agglomerate state is composed of many elongated and porous agglomerates. It is a characteristic of aerosol particles that chainlike agglomerates are formed by charged particles (Hinds 1999). While the individual particle size of the CR4 sample is smaller than that of CR1, the agglomerate size of CR4 is much larger than that of CR1. As the particle size decreases, it becomes more difficult to remove particles from surfaces when the relationship between adhesive and separating forces are taken into account (Hinds 1999). Differences in the extinction band profile in the region 13-19 $\mu \mathrm{m}$ may be especially influenced by the agglomerate state. Increasing the agglomerate size may cause the broadening of the band in this region towards longer wavelengths. As a result, a sharp fall at $13 \mu \mathrm{m}$ cannot be seen in the spectrum of CR4. In other words, the secondary peaks at $19 \mu \mathrm{m}$ increase markedly.

Comparing CR1 and CR2 (Fig. 4c), the individual particle sizes are nearly the same, but not the shape. As in the case of forsterite (Tamanai et al., in prep.), irregularly shaped particles (not round edge ones) have a tendency to produce a relatively distinctive single peak at a somewhat longer wavelength. The secondary peak at $19 \mu \mathrm{m}$ is not seen in the aerosol spectrum of CR2.

Unlike CR1, CR2, and CR4, CR3 (Fig. 4d) does not show any clear peaks between 10 and $50 \mu \mathrm{m}$ in wavelength. The secondary peak at $19 \mu \mathrm{m}$ seems to dominate. When the agglomerate state is close-packed, a broader band profile can be produced and hide the peaks from view. It is possible to confirm this trend via theoretical calculations as well (Tamanai et al. 2006a).

The theoretical models in the Rayleigh limit of a continuous distribution of ellipsoids (CDE) (Bohren \& Huffman 1983) and of spherical particles have been utilized to estimate the magnitude of the extinction profiles for the rutile samples (CR2 \& CR4). Two CDE methods have been applied to verify the shape effect on spectra. The CDE2 calculates the extinction efficiency of the most likely near-spherical particle shapes whereas the

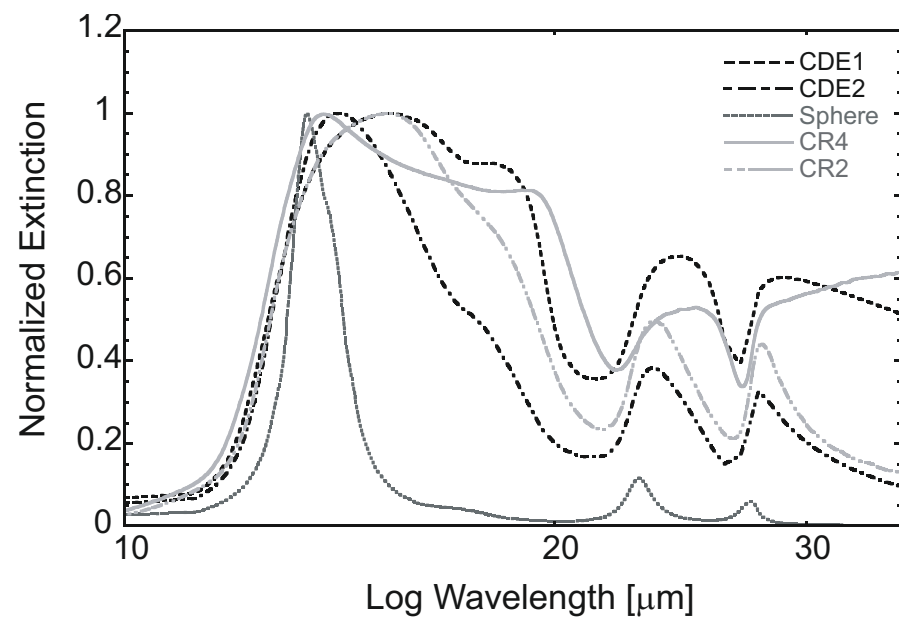

Fig. 5. Normalized extinction spectra of the two different rutile samples (CR2 \& CR4) obtained by aerosol measurements are compared with three different calculated spectra (CDE \& spheres) in air. (Note: CDE1 for equal weight of all ellipsoidal shapes \& CDE2 for preferentially near-spherical particles)

CDE1 assumes all ellipsoidal shapes with equal probability (see more details in Ossenkopf et al. 1992; Fabian et al. 2001).

Figure 5 shows the spectra taken from the aerosol measurements (CR2 \& CR4) together with the CDE1, CDE2, and Rayleigh calculations. The diameter of the model particles is $0.2 \mu \mathrm{m}$ and the optical constants from Ribarsky (1985) are applied for the theoretical calculations. The spectrum calculated for the spherical particles exhibit a sharp-pointed peak with the narrowest bandwidth. As the particles become ellipsoidal shapes, the peak undergoes a red shift, and the bandwidth gradually broadens (CDE1 \& CDE2). These calculations demonstrate the possible shape effect on the measured band profiles. The CR2 spectrum in Fig. 5 is between the spectra of the CDE1 and CDE2 in the 12-20 $\mu \mathrm{m}$ wavelength range. Figure $4 \mathrm{c}$ images show that the CR2 particles have an irregular shape; however, the band profiles of the CR2 particles, especially at 23.5 and $28 \mu \mathrm{m}$ are much closer to that calculated for near-spherical shapes. Conversely, although the CR4 particles are similarly of near-spherical shape (Fig. 4e), the CR4 measured band profile does not fit well with either the CDE1 or the CDE2 spectrum. A nearly trapezoidal profile is seen in the wavelengths between 13 and $19 \mu \mathrm{m}$. The short wavelength peak corresponds well to spherical particles. The long wavelength peak is not exactly reproduced by the CDE2. The same is true for the profile at longer wavelengths. As already mentioned, this behavior may be caused by the agglomerate effect because it is more difficult to separate particles as particles decrease in size. The effect of agglomeration is also clearly seen in the anatase spectra, specifically in the $12-25 \mu \mathrm{m}$ band complex.

CA1 (Fig. 4f) and CA2 (Fig. 4g) have very similar particle conditions. They have a particle shape with rounded edges, forming an elongated and porous type of agglomerate, and micron size particles.

CA3 (Fig. 4h) particles which are nanometer-sized, on the other hand, form many close-packed agglomerates which produce a broadening effect on the band profile. Although the particle size of the CA3 and CA4 (Fig. 4i) samples are very much alike, the agglomerate state is different. Whereas CA3 particles form more close-packed agglomerates, CA4 is composed of not only close-packed agglomerates, but also a large amount 

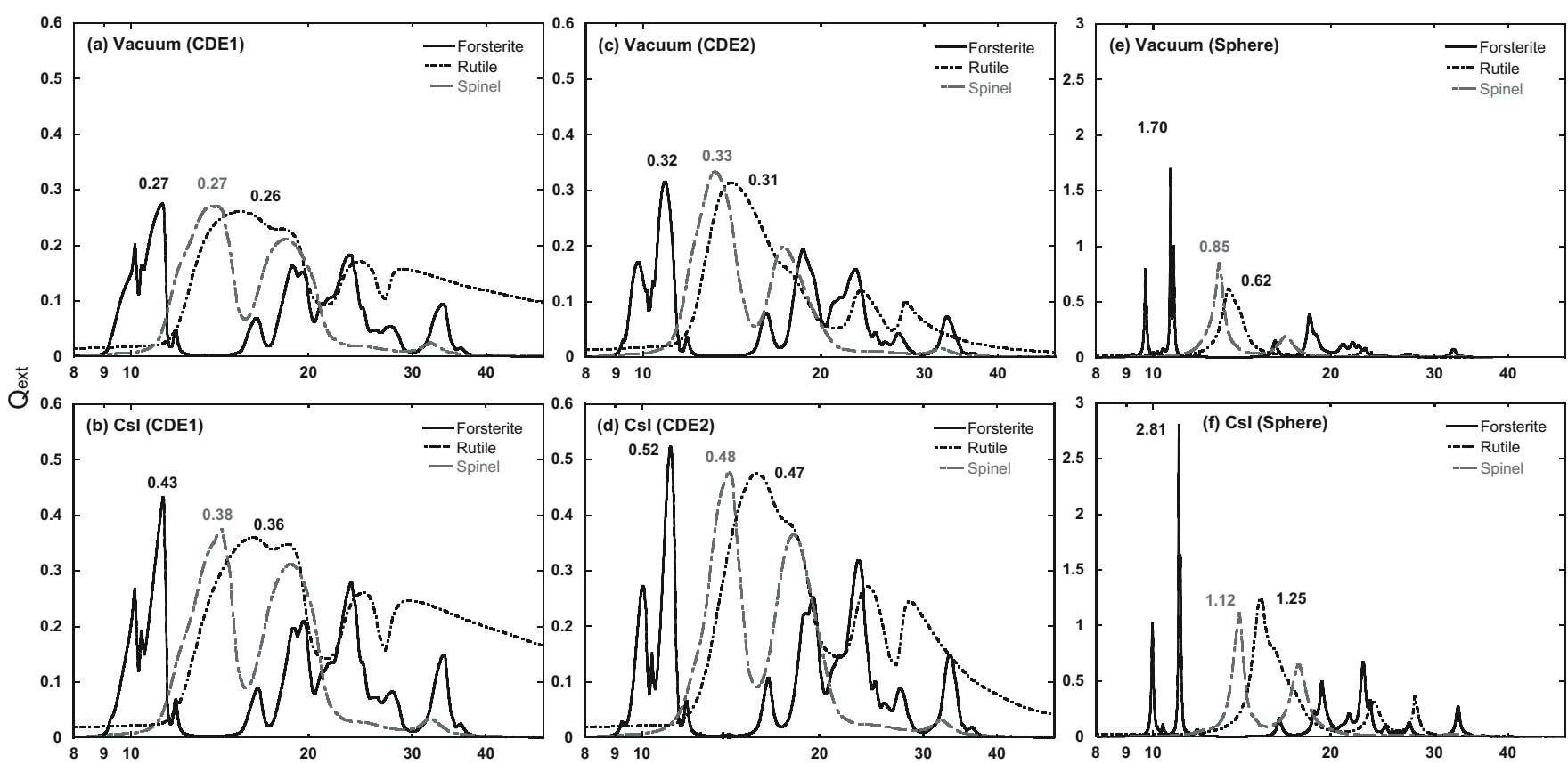

Log Wavelength $[\mu \mathrm{m}]$

Fig. 6. Extinction efficiency vs. wavelength of forsterite, rutile, and spinel spectra in vacuum (upper plots) and CsI medium (bottom plots) obtained by $\operatorname{CDE} 1(\mathbf{a}, \mathbf{b}), \operatorname{CDE} 2(\mathbf{c}, \mathbf{d})$, and sphere $(\mathbf{e}, \mathbf{f})$ calculations $(r=0.1 \mu \mathrm{m})$. Numerical extinction strengths at each peak are given in each plot.

of porous agglomerates. Consequently, the secondary band at $21 \mu \mathrm{m}$ is much stronger for CA3.

The CAC1 aerosol spectrum, in contrast, has a peak at short wavelengths, indicating near spherical shape and a trapezoidal profile because of stronger agglomeration.

Begemann et al. (1997) suggested that the $13 \mu \mathrm{m}$ band profile of $\alpha-\mathrm{Al}_{2} \mathrm{O}_{3}$ is susceptible to particle shape. The wavelength range between 13 and $20 \mu \mathrm{m}$ of $\alpha-\mathrm{Al}_{2} \mathrm{O}_{3}$ is sensitively affected by morphological effects as in the case of rutiles (Tamanai 2007). CAC1 (Fig. 4n) and CAC2 (Fig. 4o) samples differ in both the shapes and sizes of the particles. While the CAC1 particles have an irregular shape with rounded edges, CAC2 ones have an irregular shape with very sharp edges (like crushing a stone into small pieces by a hammer). As in the case of rutile (CR1 and CR2) samples, the sharp edged CAC2 particles give rise to a distinctive single peak at $14.9 \mu \mathrm{m}$ in the aerosol measurements.

CSp1 (Fig. 4r) and CSp2 (Fig. 4s) particles form a large number of agglomerates with very similar agglomerate states. However, CSp2 is composed of near-spherical grains, whereas CSp1 contains large sharp-edged particles. It is plausible that the individual particle shape exerts a stronger influence on these spectra than the agglomerate state and particle sizes. In accordance with that expectation, the spherical shaped particles produce peaks at relatively shorter wavelengths and with narrower bandwidth compared to the sharp-edged ones (see also Fig. 5). The peak for CSp2 particles is located at $13.26 \mu \mathrm{m}$ which is $0.82 \mu \mathrm{m}$ red-shifted compared to the peak of CSp1.

In general, strong extinction peaks are known to originate in geometrical resonances of the particles. Strong bands rather than the weaker ones are tremendously influenced by morphological effects and these effects are seen also in this investigation. Unfortunately it is virtually impossible to quantify the relative importance of each morphological effect. A simulation study of shape effects will be published in a forthcoming paper (Mutschke et al., in prep.).

\subsection{Quantitative measurements}

We examine the extinction strengths caused by particle shapes and embedding media via CDE and Rayleigh calculations. The model spectra of forsterite, rutile, and spinel calculated in both vacuum and CsI media are shown in Fig. 6. All the quantitative spectra are affected by the CsI in the same way. The spectra in CsI medium exhibit a factor of approximately 1.5 higher extinction strengths than those in vacuum. The extinction strengths increase as the particle configuration becomes spherical (CDE1 $\rightarrow$ sphere). We checked by CDE calculations that apart from a roughly proportional change of the absolute magnitude, spectra of particles in vacuum have the same relative peak strength as in CsI.

A comparison between the two $\mathrm{MgAl}_{2} \mathrm{O}_{4}$ (CSp1 \& CSp2) samples are shown in Fig. 7a. Although identical amounts of samples are embedded in the CsI pellets, these spectra show an enormous difference of the peak strength in the spectrum. The extinction at $14 \mu \mathrm{m}$ for CSp2 is almost twice as much as that of CSp1. It is probable that the difference in extinction between the CSp1 and CSp2 samples is chiefly caused by morphological effects, especially shape.

We compare the quantitative measured spectrum of amorphous and crystalline $\mathrm{Mg}_{2} \mathrm{SiO}_{4}$ (ellipsoidal and irregular shaped forsterites) with $\mathrm{TiO}_{2}(\mathrm{CA} 1)$ and $\mathrm{MgAl}_{2} \mathrm{O}_{4}$ (CSp2) (Fig. 7b). In the legend of Fig. 7b, the particle sizes are listed as well. These HTC spectra are of much stronger extinction strength than the amorphous $\mathrm{Mg}_{2} \mathrm{SiO}_{4}$ spectrum.

Note also that the extinction strengths of forsterite differ from the theoretical calculations for the CsI measured spectrum (Fig. 7b). As the forsterite particle shape becomes spherical, the strength of the $11 \mu \mathrm{m}$ peak becomes stronger and more prominent than the others in the calculations, but the strength of spinel in the measured spectrum is in fact the strongest in this comparison. The peak position of measured ellipsoidal forsterite takes place at $11.14 \mu \mathrm{m}$ which is closer to the peak obtained by 

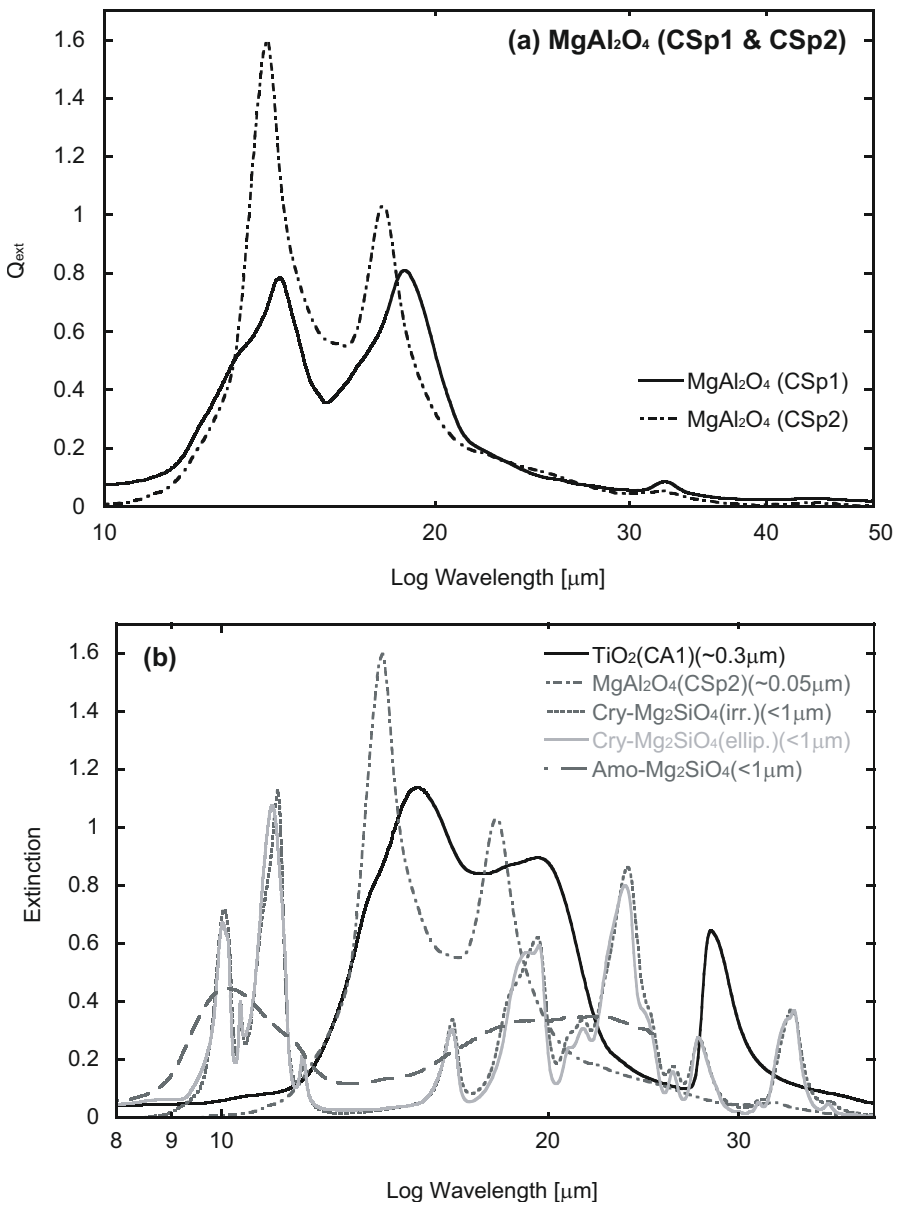

Fig. 7. a) Extinction efficiency vs. wavelength of two $\mathrm{MgAl}_{2} \mathrm{O}_{4}$ spectra (CSp1 \& CSp2) obtained by CsI pellet measurements. b) Extinction vs. wavelength of five different spectra (CA1, CSp2, crystalline forsterites (irregular and ellipsoidal shaped particles), and amorphous $\mathrm{Mg}_{2} \mathrm{SiO}_{4}$ ) obtained by CsI pellet measurements.

the calculation for spherical particles $(11.06 \mu \mathrm{m})$ compared to that of irregular shaped forsterite $(11.27 \mu \mathrm{m})$. The bandwidth of measured ellipsoidal forsterite is much broader than that of the calculated band profile, and the measured forsterite band profile does not contain any prominent peaks. On the other hand, the peak position of measured spinel is located at $14.07 \mu \mathrm{m}$ whereas the calculated peak lies at $13.99 \mu \mathrm{m}(\Delta \lambda=0.08 \mu \mathrm{m})$. The bandwidth of calculated spinel is slightly narrower than the measured one. However, the band profiles of the measured and calculated spinel spectra are comparable. This result directly affects the extinction strength. The ellipsoidal forsterite particles are not spherical enough to produce the stronger extinction strength compared to the spherical spinel. The greater extinction strength seen for forsterite is due to the shape effect of individual particles upon the extinction strength.

According to Millar (2004), amorphous silicates are conceivably the dominant species of grains, with a small amount of crystalline silicates in oxygen-rich AGB stars. As shown in Fig. 7b, amorphous $\mathrm{Mg}_{2} \mathrm{SiO}_{4}$ produces an ineffective extinction feature. If the amount of crystalline $\mathrm{Mg}_{2} \mathrm{SiO}_{4}$ is much less than that of oxides, it may be possible to detect some pronounced features from oxide dust grains in mid-IR region even if amorphous $\mathrm{Mg}_{2} \mathrm{SiO}_{4}$ is abundant.

\section{Astrophysical implication}

We selected three AGB objects which exhibit strong 13, 19.5, and $28 \mu \mathrm{m}$ features. ISO emission spectra of S Pav, Y UMa, and $g$ Her are shown in Fig. 8 together with the spectra obtained by the aerosol measurements of anatase (CA1 \& CA4), spinel (CSp2), tialite $\left(\mathrm{Al}_{2} \mathrm{TiO}_{5}\right)$ and amorphous $\mathrm{Mg}_{2} \mathrm{SiO}_{4}$ (Tamanai et al. 2006b) in the wavelength range between 8 to $45 \mu \mathrm{m}$. Basic properties and detailed observed data analysis information of these AGB objects are given in Posch et al. (1999), Posch et al. (2002), and Fabian et al. (2001).

The emission spectra of S Pav and Y UMa (Figs. 8a, b) show a strong and broad $9-40 \mu \mathrm{m}$ background. An $11 \mu \mathrm{m}$ peak, which is clearly seen in both spectra, may originate from amorphous $\mathrm{Al}_{2} \mathrm{O}_{3}$ (Cami 2002). In contrast, the emission spectrum of g-Her (Fig. 8c) has a weaker background and a clear $10 \mu \mathrm{m}$ amorphous silicate band (Millar 2004). The $10 \mu \mathrm{m}$ band appears as a shoulder only in the spectra of S Pav and Y UMa. These spectra exhibit bands at 13, 16-22 (equally strong, with substructures), 28, and $32 \mu \mathrm{m}$ (weak, especially in S Pav; apparently quite strong in g-Her). The relative strength of the bands may be a temperature effect.

A strong $13 \mu \mathrm{m}$ feature appears in all three objects as well as 19.5 and $28 \mu \mathrm{m}$ features. Anatase, spinel and tialite produce peaks around $13 \mu \mathrm{m}$, but the anatase (CA1) peak $(13.1 \mu \mathrm{m})$ corresponds best with the $13 \mu \mathrm{m}$ feature of the observed spectra. However, the $13 \mu \mathrm{m}$ feature in the observed spectra is rather a prominent peak. It is possible that spinel (like CSp2) enhances the protuberance of the $13 \mu \mathrm{m}$ peak.

As mentioned in Sect. 3.2, the wavelength range between 13 and $20 \mu \mathrm{m}$ of the $\mathrm{TiO}_{2}$ spectra is finely influenced by morphological effects. Figures $8 \mathrm{~d}$ and e show the two types of anatase spectra that exhibit different band profiles caused by morphological effects (Table 1). As the morphological state of the particles varies, the band profile is noticeably changed as well. Consequently, it may be that anatase particles with a different morphological state are able to enhance the $13 \mu \mathrm{m}$ peak and/or to produce a clearer peak around $19 \mu \mathrm{m}$.

Additionally, we consider that tialite plays an important role in the observed spectra. When all these HTCs $\left(\mathrm{Al}_{2} \mathrm{O}_{3}, \mathrm{TiO}_{2}\right.$, $\mathrm{MgAl}_{2} \mathrm{O}_{4}$ ) are present in the same environment, tialite and more complex titanate dust grain formation is expected (see Sect. A.6.). According to Buscaglia et al. (1996), $\mathrm{MgAl}_{2} \mathrm{O}_{4}$ and $\mathrm{TiO}_{2}$ react into $\mathrm{Mg}_{0.5} \mathrm{AlTi}_{1.5} \mathrm{O}_{5}$ particles which are formed at a temperature above $\approx 1423 \mathrm{~K}$. These behave like nuclei for further titanate (e.g. $\mathrm{AlTiO}_{3}, \mathrm{MgTiO}_{3}, \mathrm{MgTi}_{2} \mathrm{O}_{5}, \mathrm{Al}_{2} \mathrm{TiO}_{5}$ ) formation and growth. Consequently, $\mathrm{MgAl}_{2} \mathrm{O}_{4}$ produces an effect on the mechanism of $\mathrm{Al}_{2} \mathrm{TiO}_{5}$ formation. If spinel dust grains exist in an environment, $\mathrm{Mg}$ containing titanate may form (see also Posch et al. 2003). This is also an interesting point to associate with a subsequent condensation process in the outflow of AGB stars. From the spectroscopic point of view, although the $13 \mu \mathrm{m}$ peak of tialite is not as prominent of the peak in CSp2, this peak is expected to enhance the strength of the emission in the observed spectra.

As to the peak at $19.5 \mu \mathrm{m}$, none of the measured spectra produced a peak adequate to explain the observed spectra. However, the observed peak at $19.5 \mu \mathrm{m}$ might be contributed by anatase dust grains because the three observed spectra in Fig. 8 have a common feature, namely that the emission strength of the $13 \mu \mathrm{m}$ feature correlates with that of the $19.5 \mu \mathrm{m}$ peak. g-Her (Fig. 8c) shows the narrowest and sharpest 13 and $19 \mu$ m peaks among the observed spectra while $\mathrm{S}$ Pav exhibits a broader peak at $13 \mu \mathrm{m}$, and then the $19.5 \mu \mathrm{m}$ peak becomes more like a small shoulder. 


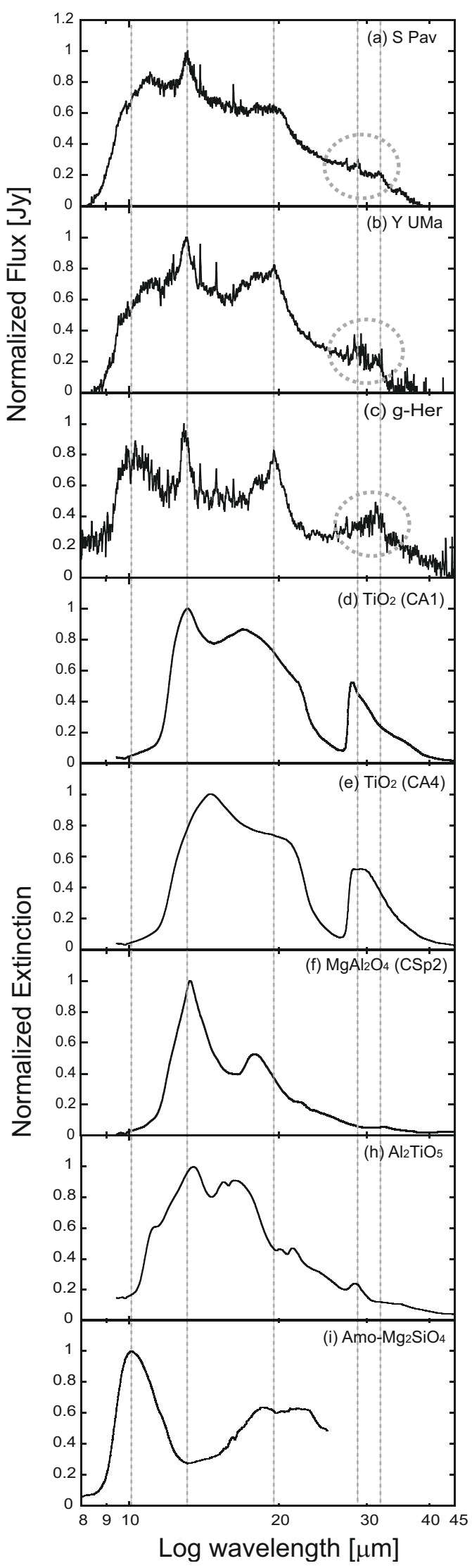

Fig. 8. Comparison of the observed emission features for the three AGB stars with the experimental results. The normalized emission spectrum of a) S Pav; b) Y UMa; c) g Her are compared with the aerosol measurements of d) anatase (CA1); e) anatase (CA4); f) spinel (CSp2); g) tialite $\left.\left(\mathrm{Al}_{2} \mathrm{TiO}_{5}\right) ; \mathbf{h}\right)$ amorphous $\mathrm{Mg}_{2} \mathrm{SiO}_{4}$. The gray dotted lines denote 11 , $13,19.5,28$ and $32 \mu \mathrm{m}$ wavelengths.
Sloan et al. (2003) discussed about the correlated dust features at 13,20 and $28 \mu \mathrm{m}$ and concluded that the 20 and $28 \mu \mathrm{m}$ features originated in silicates. Posch et al. (2002) proposed that the $19.5 \mu \mathrm{m}$ feature carrier would be $\mathrm{Mg}_{0.1} \mathrm{Fe}_{0.9} \mathrm{O}$ in relation to the band profiles (the band width, shape and position), but the formation of $\mathrm{Mg}_{0.1} \mathrm{Fe}_{0.9} \mathrm{O}$ in the circumstellar environment is not yet well understood. We expect that all three peaks $(13,19.5$ and $28 \mu \mathrm{m}$ ) come from a single source. The observed spectra undergo a slight change in the band profiles (e.g. peak shift, band broadening, and the strength of extinction feature) by other relatively less influential sources. In order to clarify the source of the $19.5 \mu \mathrm{m}$ feature, it is necessary to take morphological effects into account and to carry out further investigation.

Another point to be investigated is the band feature beyond $19.5 \mu \mathrm{m}$. The observed spectra exhibit a gradual fall beyond $19.5 \mu \mathrm{m}$, and excessive extinction features cannot be seen in this wavelength region. In fact, rutile is the most stable material out of the three crystalline phases of $\mathrm{TiO}_{2}$ (see Sect. A.2.). However, the anatase spectra fit better with these observed spectra since they do not show any peaks around $25 \mu \mathrm{m}$, unlike the rutile spectra (Figs. 4b-e). The minor peaks circled $(\approx 28 \mu \mathrm{m})$ in Figs. 8a-c fit well with the anatase features (CA1 \& CA2) as well as with tialite.

Furthermore, as mentioned above, the $10 \mu \mathrm{m}$ feature originates from amorphous silicate (Millar 2004). In this investigation, the amorphous $\mathrm{Mg}_{2} \mathrm{SiO}_{4}$ spectrum obtained by aerosol measurement compares well with the $10 \mu \mathrm{m}$ feature, especially for the spectrum of $\mathrm{g}$-Her.

\section{Summary and discussions}

Spectroscopic extinction measurements of HTCs are performed in the wavelength range between 10 and $50 \mu \mathrm{m}$ by making use of the aerosol technique in order to obtain the band profiles without any medium effect. We focus particularly on morphological effects on the measured spectra to obtain a new perspective on the $13,19.5$, and $28 \mu \mathrm{m}$ carriers in the spectra of AGB stars. We summarize the main results of this paper as follows:

- There is a tendency for peaks to appear at longer wavelengths due to the influence of the medium on the surface modes. The effect is expected (Bohren \& Huffman 1983), but is very strong for many HTCs. The maximum peak position difference between the aerosol and CsI pellet measurement is $3.20 \mu \mathrm{m}$ in wavelength in the case of the $\mathrm{TiO}_{2}$ anatase (CA4) sample.

- Particles which have spherical or roundish shapes produce larger differences between the spectra measured by the aerosol and the CsI pellet techniques as compared to the irregular shaped particles.

- Roundish grains tend to produce double peaked (rectangular) profiles in comparison with irregular shaped grains.

- The agglomerate state may strongly influence the strength of the strong bands. The extinction band profile between 13 and $19.5 \mu \mathrm{m}$ undergoes a substantial change for different agglomerate states (rutile \& anatase).

- Although band profiles are influenced by the morphological effects, it is practically unfeasible to quantify the relative importance of each morphological effect.

- In comparison to $\mathrm{TiO}_{2}, \mathrm{Al}_{2} \mathrm{O}_{3}$ creates a larger disparity in the band profiles. In particular, three different crystal structures have been detected by a X-ray diffraction analysis in $\chi-\delta-\kappa-\mathrm{Al}_{2} \mathrm{O}_{3}$ that produce 25 discernible peaks up to $45 \mu \mathrm{m}$. 
- The absolute strength of extinction strongly depends on chemical composition and particle morphology. Spherical shaped nano-sized spinel shows the most effective extinction in all samples investigated here.

- Through the comparison of the observed emission in AGB spectra and the aerosol spectra, we find that primarily the roundish edged anatase (CA1) is anticipated to contribute to the 13 and $28 \mu \mathrm{m}$ peaks. Spherical shaped nano-sized spinel (CSp2) plays a role in intensifying the $13 \mu \mathrm{m}$ peak as well as tialite $\left(\mathrm{Al}_{2} \mathrm{TiO}_{5}\right)$. The carrier for the peak at $19.5 \mu \mathrm{m}$ could not be identified well in this investigation. However, as a possibility, the $19.5 \mu \mathrm{m}$ peak might be produced by the same source (anatase) when the particle morphology and temperature are taken into account.

In fact, titanium is a significantly less abundant metal by a factor of 400, compared to Si (Cameron 1973). Posch et al. (2003) noted that rutile and anatase in the $13 \mu \mathrm{m}$ region are about 40 times more effective absorbers than amorphous silicate, and they predicted that the most prominent $\mathrm{TiO}_{2}$ emission will be about $1 / 10$ th as strong as the silicate dust emission. Likewise, our CsI pellet measurements exhibit very similar results, and show that anatase radiates approximately 8.5 times more efficiently than amorphous $\mathrm{Mg}_{2} \mathrm{SiO}_{4}$. However, there is still a huge difference between the abundance proportions of $\mathrm{Ti}$ and $\mathrm{Si}$. If the solar abundance can be applied in the AGB star environments, the $\mathrm{Ti}$ abundance remains unclear.

The abundance of possible condensates has been calculated under the assumption of chemical equilibrium. Chemical equilibrium cannot apply to the dust condensation process in circumstellar dust shells since grain formation takes place in a non-equilibrium kinetic process. The non-equilibrium calculations of Ferrarotti \& Gail (2001) showed that a different mixture of minerals form compared to an equilibrium calculation. Although the equilibrium assumption may be very convenient as an approximation to understand possible condensates present in certain conditions, the detailed condensation process can only be explored with non-equilibrium calculations. More dependable non-equilibrium condensation process results are required to study further dust grain formation in the circumstellar outflow of AGB stars.

While having a precise knowledge of the absolute strength of extinction for each substance is essential to identify the dust grains present in dust shells, it is also very important to understand heterogeneous dust grain properties. We have concentrated only on homogeneous dust grain investigations here. Each sample has unique properties which determine the agglomerate state. The agglomeration of non-spherical particles increases in comparison to spherical particles with the same volume because the non-spherical particles have a larger surface area which leads to more collisions by Brownian motion (e.g. Hinds 1999; Blum et al. 2000; Krause \& Blum 2004; Paszun \& Dominik 2006). As the particle shape irregularity becomes much more complicated, the agglomeration effect will be more significant. According to a theoretical calculation by Zebel (1966), ellipsoidal particles have a $35 \%$ higher agglomeration coefficient than spherical ones with the same volume. Hence, heterogeneous grains make both the thermal and kinematic agglomeration processes more complicated. An experimental heterogeneous dust grain investigation is indispensable to address this problem.

By way of another approach, we will attempt to mix crystalline and amorphous samples together so as to observe how these mixed particles interact with each other and produce an effect on the band profiles. We focused only on crystalline dust particles in this investigation, since we presume that the $13 \mu \mathrm{m}$ peak mainly originates from a crystalline species. Unlike crystalline materials, amorphous particles tend to produce broader bands due to the range of bond lengths and angles of atoms in the amorphous structure (Jäger et al. 2003). However, as the three observed AGB spectra (Fig. 8) show broad peaks between 10 and $13 \mu \mathrm{m}$, it is recognizable that amorphous materials (e.g. silicates) take part in the spectra. Posch et al. (2002) proposed that amorphous $\mathrm{Al}_{2} \mathrm{O}_{3}$ contributes a broad "continuum emission" (g Her, Y UMa, V1943 Sgr) in the wavelength range between 11 and $15 \mu \mathrm{m}$. Thus, it is interesting to examine how the strong crystalline features are weakened by amorphous materials by changing the quantity of each material.

During aerosol measurements, the large and compact agglomerates start to be deposited in the cell; therefore, only the remaining small and fluffy agglomerates can keep flying in the cell for a long time. These aerosol spectra reflect the difference in bandwidth. A spectrum from a sample which contains more large agglomerates shows broader bands. However, the variation of these spectra is not very strong. Since the particle densities are too low $\left(10^{6}\right.$ particles $\left./ \mathrm{cm}^{3}\right)$ and the gas pressure is too high, these experiments are not a suitable environment to observe the growth of particles by agglomeration.

Concerning the quantitative aspects of the aerosol measurements, it is extremely difficult to obtain the exact mass concentration in the cell during the measurements. One of the possible ways to solve this problem is to derive the mass through a theoretical analysis. The extinction efficiency of small-sized particles can be calculated by means of the form-factor distribution (Min et al. 2006) which can then be fitted to the measured spectrum. A forthcoming paper will include more discussion of these concepts (Mutschke et al., in prep.).

Identification of dust grains in astrophysical environments is not straightforward. The band profiles are strongly influenced by physical and chemical factors of the dust grains which interact with each other and make the identification all the more complicated. It is essential to carry out condensation experiments and more detailed non-equilibrium condensation theoretical approaches for the circumstellar dust shells around AGB stars.

The infrared extinction spectra database can be found at http://elbe.astro.uni-jean.de. The database includes the numerical extinction efficiency data obtained by both the aerosol and CsI pellet measurements, SEM and TEM images, basic properties, plots, and peak positions of each sample.

Acknowledgements. We express to the members of the pathology department at FSU Jena, Dr. S. Nietzsche, F. Steiniger, and C. Kamnitz our gratitude for the technical support of the TEM and SEM. We are thankful to Dr. D. R. Alexander at ISU and Dr. D. Hilditch at FSU Jena (TPI) for proofreading and insightful opinions and comments. We are grateful to G. Born for her assistance with sample preparation and W. Teuschel for his technical support of our experimental devices. Our project has been supported by Deutsche Forschungsgemeinschaft (DFG) under the grant MU 1164/6.

\section{Appendix A: Physical properties of oxides}

\section{A.1. TiO}

Titanium oxide, $\mathrm{TiO}_{x}(0.7 \leq x \leq 1.25)$, forms in a cubic crystal structure (Jun et al. 1984). TiO is the one-to-one composition of the $\mathrm{TiO}_{x}$ series and has a defective $\mathrm{NaCl}$ crystal structure which is composed of identical numbers of random vacancies in the cation and anion sites in cubic symmetry at temperatures higher than 1273 K (Fujimura et al. 1989; Wells 1991). However, the cubic crystal structure of $\mathrm{TiO}_{x}$ can be transformed into various ordered structures such as cubic, tetragonal, orthorhombic, 
and monoclinic lattices. The transformation depends strongly on oxygen content and temperature conditions (Jun et al. 1984; Gusev 1991). The melting point of $\mathrm{TiO}$ is $2023 \mathrm{~K}$ (Lide 1990) which is the lowest temperature among the Ti-compounds investigated here.

Solid TiO forms from $\mathrm{TiO}_{2}$ and $\mathrm{H}_{2}$ gases through the chemical reaction in the circumstellar outflow of $\mathrm{M}$ stars

$\mathrm{TiO}_{2}$ (gas) $+\mathrm{H}_{2} \longrightarrow \mathrm{TiO}($ solid $)+\mathrm{H}_{2} \mathrm{O}$

(Gail \& Sedlmayr 1998).

\section{A.2. $\mathrm{TiO}_{2}$}

Titanium dioxide (titanium (IV) oxide or titania) $\left(\mathrm{TiO}_{2}\right)$ occurs in three different crystal structures, which are stable at atmospheric pressure. They are rutile, anatase, and brookite. Although the anatase and brookite phases are stable at lower temperature than rutile, both transform to rutile at approximately $1188 \mathrm{~K}$ (anatase) and $1023 \mathrm{~K}$ (brookite) (Brandes \& Brook 1992). Rutile is the most stable form of the three phases. It belongs to the tetragonal crystal system and has a melting point at $2123 \mathrm{~K}$ (Lide 1990). Anatase is a member of the tetragonal crystal system as well. The density of anatase is approximately $10 \%$ less than that of rutile (Linsebigler et al. 1995). The melting point of anatase, which is about $2108 \mathrm{~K}$ (Reade Advanced Materials 1997), is slightly lower than that of rutile.

In the crystal structure system, rutile and anatase consist of the basic structural unit of the $\mathrm{TiO}_{6}$ octahedron. Each $\mathrm{Ti}^{+4}$ ion occupies the center of the oxygen octahedra, so that it is surrounded by $6 \mathrm{O}^{2-}$ ions. Conversely, since each $\mathrm{O}^{2-}$ ion is enclosed by $3 \mathrm{Ti}^{4+}$ ions, the Ti:O ratio will be $3: 6$. In both cases, $\mathrm{TiO}_{2}$ octahedra are distorted, and anatase has more distortions than rutile (see details in e.g. Mo et al. 1995; Klein \& Hurlbut 1993; Muraishi 2004).

$\mathrm{TiO}_{2}$ solid would form from the gas phase via

$\mathrm{TiO}_{2}$ (gas) $\longrightarrow \mathrm{TiO}_{2}$ (solid)

(Gail \& Sedlmayr 1998). Solid $\mathrm{TiO}_{2}$ (rutile) contributes to $\mathrm{Al}_{2} \mathrm{TiO}_{5}$ formation (see 2.2.6).

In addition, when a deposited $\mathrm{TiO}$ thin film underwent annealing in air, anatase and rutile structures have been shown at a temperature of $793 \mathrm{~K}$ (Zribi et al. 2008), which indicates possible $\mathrm{TiO}_{2}$ formation from $\mathrm{TiO}$ via an annealing process.

The optical properties of $\mathrm{TiO}_{2}$ (rutile, brookite, anatase) are found in Posch et al. (2003).

\section{A.3. $\mathrm{Ti}_{2} \mathrm{O}_{3}$}

Dititanium trioxide $\left(\mathrm{Ti}_{2} \mathrm{O}_{3}\right)$ has a trigonal crystal structure. $\mathrm{O}^{2-}$ ions are positioned in a hexagonal close-packed structure and $\mathrm{Ti}^{3+}$ ions occupy $2 / 3$ of the octahedral interstices (Wells 1991). $\mathrm{Ti}_{2} \mathrm{O}_{3}$ has a corundum-type structure (see Sect. A.7.) at all temperatures (Straumanis \& Ejima 1962). The melting point is $2503 \mathrm{~K}$, which is much higher than that of $\mathrm{TiO}_{2}$.

A possible solid $\mathrm{Ti}_{2} \mathrm{O}_{3}$ formation pathway from the gas phase is

$2 \mathrm{TiO}_{2}$ (gas) $+\mathrm{H}_{2} \longrightarrow \mathrm{Ti}_{2} \mathrm{O}_{3}$ (solid) $+\mathrm{H}_{2} \mathrm{O}$

(Gail \& Sedlmayr 1998). Reflectance measurements of a single $\mathrm{Ti}_{2} \mathrm{O}_{3}$ crystal sample at room-temperature have been performed by Lucovsky et al. (1977). The measurements were made for the two primary polarizations, namely with the crystalline c-axis perpendicular and parallel to the plane of incidence. The
TO-phonon frequencies obtained with the perpendicular measurements were 19.6, 22.2, 26.6, and $35.7 \mu \mathrm{m}$ and 18.6, 19.9, 25.6 , and $35.6 \mu \mathrm{m}$ for the LO modes. Likewise, the parallel measurements of the TO-phonon frequencies were shown at 22.3 and $29.2 \mu \mathrm{m}$, and 18.1 and $28.5 \mu \mathrm{m}$ for the LO modes (see also Posch et al. 2003).

\section{A.4. $\mathrm{Ti}_{3} \mathrm{O}_{5}$}

Trititanium pentoxide is one of the $\mathrm{Ti}_{n} \mathrm{O}_{2 n-1}(n \geq 4)$ series. Åsbrink \& Magnéli (1959) ascertained the $\mathrm{Ti}_{3} \mathrm{O}_{5}$ crystal structure at room temperature to be monoclinic. The crystal structure of $\mathrm{Ti}_{3} \mathrm{O}_{5}$ is composed of a three dimensional array of $\mathrm{TiO}_{6}$ octahedra sharing edges and vertices (Wells 1991). However, $\mathrm{Ti}_{3} \mathrm{O}_{5}$ is also a substance which undergoes phase transitions of crystal structures during heating. A transition from monoclinic to orthorhombic phases has been seen at a temperature of $514 \mathrm{~K}$ (Onoda 1998).

$\mathrm{Ti}_{3} \mathrm{O}_{5}$ may form via the chemical reaction

$$
3 \mathrm{TiO}_{2}(\text { gas })+\mathrm{H}_{2} \longrightarrow \mathrm{Ti}_{3} \mathrm{O}_{5}(\text { solid })+\mathrm{H}_{2} \mathrm{O}
$$

(Gail \& Sedlmayr 1998). The melting point of $\mathrm{Ti}_{3} \mathrm{O}_{5}$ is $2033 \mathrm{~K}$ (International Advanced Materials 1999) which is slightly lower than anatase and rutile. The stretching vibration of $\mathrm{TiO}_{6}$ octahedra takes place in the wavelength range between 4.3 and $16.7 \mu \mathrm{m}$ $\left(600-700 \mathrm{~cm}^{-1}\right)$ (Gillet 1993) similarly to other Ti-compounds.

\section{A.5. $\mathrm{CaTiO}_{3}$}

According to the relative abundances of dust grain calculations (Sect. 2.3) (Fig. 2), $\mathrm{CaTiO}_{3}$ (perovskite) appears at approximately $1700 \mathrm{~K}$ in chemical equilibrium before a large quantity of silicates starts to condense out of the gas. Solid perovskite may form via the chemical reaction

$\mathrm{TiO}_{2}($ gas $)+\mathrm{Ca}+\mathrm{H}_{2} \mathrm{O} \longrightarrow \mathrm{CaTiO}_{3}($ solid $)+\mathrm{H}_{2}$.

$\mathrm{Ca}$ exists as a free atom in the gas phase because $\mathrm{Ca}$ atoms are not able to form high bond energy molecules (Gail \& Sedlmayr 1998). The melting point of perovskite is approximately $2248 \mathrm{~K}$ (Alfa Aesar Catalog) which is the second highest value among Ti-compounds.

Perovskite has an orthorhombic crystal system and a face centered cubic lattice (fcc) (e.g. Redfern \& Carpenter 2000). Eight smaller $\mathrm{Ti}^{+4}$ cations are located at each corner of the cubic structure, and the large $\mathrm{Ca}^{+2}$ cation occupies the center. Twelve $\mathrm{O}^{2-}$ anions are positioned between each $\mathrm{Ti}^{4+}$ cation. Thus, the $\mathrm{Ca}^{2+}$ cation is surrounded by the $12 \mathrm{O}^{2-}$ and $8 \mathrm{Ti}^{4-}$ cations with a coordinate distance to form the cubic close-packed structure which is sustained only if the 12 -fold coordinated $\mathrm{Ca}^{2+}$ cation is larger than oxygen. Otherwise, the cubic crystal structure undergoes a distortion to transform into other crystal forms such as octahedra, tetragonal, orthorhombic, and monoclinic forms depending on the temperature. Once the face-centered cubic lattice loses its shape due to a change in temperature down to the Curie point, perovskite becomes a ferroelectric material that has a very high dielectric constant (e.g. Douglas \& Ho 2006). The origin of $\mathrm{CaTiO}_{3}$ IR absorption mainly arises from Ti-O stretching modes around $18.2 \mu \mathrm{m}\left(550 \mathrm{~cm}^{-1}\right)$ and $22.5 \mu \mathrm{m}\left(445 \mathrm{~cm}^{-1}\right)$, Ti-O-Ti bending mode at $55.6 \mu \mathrm{m}\left(180 \mathrm{~cm}^{-1}\right)$, and the cation- $\mathrm{TiO}_{3}$ lattice mode at $66.7 \mu \mathrm{m}\left(150 \mathrm{~cm}^{-1}\right)$ (Perry \& Khanna 1964).

Posch et al. (2003) derived optical constants of a natural $\mathrm{CaTiO}_{3}$ crystal from reflectance measurements. 


\section{A.6. $\mathrm{Al}_{2} \mathrm{TiO}_{5}$}

We considered that aluminum titanate (tialite or $\mathrm{Al}_{2} \mathrm{TiO}_{5}$ ) is a very interesting species to investigate, though it has not been discovered yet in any astronomical objects. $\mathrm{Al}_{2} \mathrm{TiO}_{5}$ can be formed above its equilibrium formation temperature, $1553 \mathrm{~K}$ (Freundenberg \& Mocellin 1987, 1988). The formation of $\mathrm{Al}_{2} \mathrm{TiO}_{5}$ via the endothermic reaction would be

$\alpha-\mathrm{Al}_{2} \mathrm{O}_{3}$ (corundum) $+\mathrm{TiO}_{2}$ (rutile) $\longrightarrow \beta-\mathrm{Al}_{2} \mathrm{TiO}_{5}$

(e.g. Woignier et al. 1988; Jianu et al. 2003). The melting point of $\mathrm{Al}_{2} \mathrm{TiO}_{5}$ is rather high $(2133 \mathrm{~K})$, as for $\mathrm{Al}_{2} \mathrm{O}_{3}$ and $\mathrm{TiO}_{2}$ (Jianu et al. 2003). Although it is possible to maintain $\mathrm{Al}_{2} \mathrm{TiO}_{5}$ under metastable conditions at room temperature, the decomposition takes place at a temperature above $1123 \mathrm{~K}$ (Woignier et al. 1988). The reaction between corundum and rutile into $\mathrm{Al}_{2} \mathrm{TiO}_{5}$ begins at $1473 \mathrm{~K}$. As the temperature increases to $1523 \mathrm{~K}$, $\mathrm{Al}_{2} \mathrm{TiO}_{5}$ dominates in quantity (Jianu et al. 2003). $\mathrm{Al}_{2} \mathrm{TiO}_{5}$ belongs to the orthorhombic pseudobrookite-type crystal structure, which is composed of $\mathrm{MO}_{6}$ octahedra sharing edges and vertices (M denotes metal) (Wells 1991). Ti-O and Al-O vibrations induce absorption at wavelengths between 13.3 and $25 \mu \mathrm{m}$ (750-400 $\left.\mathrm{cm}^{-1}\right)$. In detail, the stretching modes from octahedral $\mathrm{AlO}_{6}$ appear between 13.3 and $16.7 \mu \mathrm{m}\left(750-600 \mathrm{~cm}^{-1}\right)$, and the bending mode occurs approximately at $22.2 \mu \mathrm{m}\left(450 \mathrm{~cm}^{-1}\right)$. By the same token, $\mathrm{TiO}$ stretching vibration modes are induced below $13.7 \mu \mathrm{m}\left(730 \mathrm{~cm}^{-1}\right)$ in wavelength and tetrahedral coordinated Al-O produces peaks around 11.8 to $13.3 \mu \mathrm{m}(850$ $750 \mathrm{~cm}^{-1}$ ) (e.g. Preudhomme \& Tarte 1971; Stanciu et al. 2004).

While $\mathrm{Al}_{2} \mathrm{TiO}_{5}$ may be sufficiently less abundant to not be visible in observed spectra, the formation of $\mathrm{Al}_{2} \mathrm{TiO}_{5}$ is possible via the chemical reaction of corundum and rutile.

\section{A.7. $\mathrm{Al}_{2} \mathrm{O}_{3}$}

Aluminum oxides crystallize into the form of corundum ( $\alpha$ $\mathrm{Al}_{2} \mathrm{O}_{3}$ ), which is the second hardest natural mineral. This hardness might be caused by the strong and short $\mathrm{O}-\mathrm{Al}$ ionic bonds which attract $\mathrm{O}^{2-}$ ions and $\mathrm{Al}^{3+}$ ions close together in order to form a tremendously hard and dense close-packed crystal structure. $\alpha-\mathrm{Al}_{2} \mathrm{O}_{3}$ is formed from aluminum hydroxides via many phase transitions by increasing calcination temperature. Take boehmite $(\mathrm{AlO}(\mathrm{OH}))$, for instance. The dehydration reaction pathway of boehmite is that it is first transformed into $\gamma-\mathrm{Al}_{2} \mathrm{O}_{3}$ $(750 \mathrm{~K}) \rightarrow \delta-\mathrm{Al}_{2} \mathrm{O}_{3}(1050 \mathrm{~K}) \rightarrow \theta-\mathrm{Al}_{2} \mathrm{O}_{3}(\approx 1200 \mathrm{~K}) \rightarrow \alpha-\mathrm{Al}_{2} \mathrm{O}_{3}$ $(\approx 1300 \mathrm{~K})$ (Wefers \& Misra 1987). $\delta-\mathrm{Al}_{2} \mathrm{O}_{3}$ has a tetragonal crystal structure like $\gamma-\mathrm{Al}_{2} \mathrm{O}_{3}$. On the one hand, in the dehydration reaction pathway of gibbsite $\left(\mathrm{Al}(\mathrm{OH})_{3}\right)$ is first changed to $\chi-\mathrm{Al}_{2} \mathrm{O}_{3}(473-1173 \mathrm{~K}) \rightarrow \kappa-\mathrm{Al}_{2} \mathrm{O}_{3}(1173-1273 \mathrm{~K}) \rightarrow \alpha-\mathrm{Al}_{2} \mathrm{O}_{3}$ $\left(>1273 \mathrm{~K}\right.$ ) (Coelho et al. 2007). $\kappa-\mathrm{Al}_{2} \mathrm{O}_{3}$ has hexagonal and orthorhombic crystal structures whereas the crystal systems of $\chi-\mathrm{Al}_{2} \mathrm{O}_{3}$ are hexagonal and cubic (Bhattacharya et al. 2004). All the phases are metastable polymorphs of transition $\mathrm{Al}_{2} \mathrm{O}_{3}$ except $\alpha-\mathrm{Al}_{2} \mathrm{O}_{3}$ which is always the end product. A reverse transition is also able to produce one or more metastable or transition $\mathrm{Al}_{2} \mathrm{O}_{3}$ molecules. $\gamma-\mathrm{Al}_{2} \mathrm{O}_{3}$ is the most common resultant from $\alpha-\mathrm{Al}_{2} \mathrm{O}_{3}$ by cooling (Santos et al. 2000).

$\alpha-\mathrm{Al}_{2} \mathrm{O}_{3}$ has a rhombohedral (or trigonal) crystal structure and is considered to be one of the early condensation species in a cooling gas environment of solar composition (Begemann et al. 1997). The melting point is in the range between 2273 and $2303 \mathrm{~K}$ (Lide 1990). In the crystal structure of $\alpha-\mathrm{Al}_{2} \mathrm{O}_{3}$, the $\mathrm{O}^{2-}$ ions are arranged in a hexagonal close-packing structure, and the $\mathrm{Al}^{3+}$ ions occupy $2 / 3$ of the octahedral interstices.
One $\mathrm{Al}^{3+}$ ion is surrounded by $6 \mathrm{O}^{2-}$ ions whereas one $\mathrm{O}^{2-}$ ion is enclosed within $4 \mathrm{Al}^{3+}$ ions. Thus, the $\mathrm{Al}: \mathrm{O}$ ratio will be $4: 6$ (e.g. Muraishi 2004).

$\gamma-\mathrm{Al}_{2} \mathrm{O}_{3}$ has a tetragonal crystal structure (Saalfeld 1958). $\gamma-\mathrm{Al}_{2} \mathrm{O}_{3}$ is a so-called "defect-spinel" because it has basically the same structure as spinel (e.g. Streitz \& Mintmire 1999). Since $\gamma-\mathrm{Al}_{2} \mathrm{O}_{3}$ does not have $\mathrm{Mg}$ cations, $\mathrm{Al}$ cations occupy the $\mathrm{Mg}$ sites. As a result, the stoichiometry becomes $\mathrm{Al}_{3} \mathrm{O}_{4}$. It is necessary to remove $8 / 3 \mathrm{Al}^{3+}$ ions from the 24 ions available in the spinel unit cell in order to correct the stoichiometry. Then, the unit cell contains $96 \mathrm{O}^{2-}$ ions, $64 \mathrm{Al}^{3+}$ ions, and 8 spinel cation vacancies. These vacancies are randomly distributed; exact locations have not been verified (e.g. Streitz \& Mintmire 1999).

The equilibrium between a condensed phase and vapor phase can be represented in the case of $\alpha-\mathrm{Al}_{2} \mathrm{O}_{3}$ as

$2 \mathrm{Al}($ gas $)+3 \mathrm{O}($ gas $) \longrightarrow \alpha-\mathrm{Al}_{2} \mathrm{O}_{3}($ solid $)$

(Grossman \& Larimer 1974).

Al-O vibrations are induced in the mid-IR region (Begemann et al. 1997). LO modes were confirmed around 15.74, 17.57, 22.62 , and $25.97 \mu \mathrm{m}\left(635,569,442\right.$, and $\left.385 \mathrm{~cm}^{-1}\right)$ with the electric field polarized perpendicular to the c-axis (ordinary ray) whereas LO modes around 11.11, 16.0, 20.83, and $25.77 \mu \mathrm{m}$ $\left(900,625,480\right.$, and $\left.388 \mathrm{~cm}^{-1}\right)$ were observed with the ordinary ray. Likewise, the TO mode peaks at approximately 15.29 , 17.15 , and $25.00 \mu \mathrm{m}\left(654,583\right.$, and $\left.400 \mathrm{~cm}^{-1}\right)$ appeared with the electric field polarized parallel to the c-axis (extraordinary ray). The LO modes of the extraordinary ray could be detected at about 11.48 and $19.53 \mu \mathrm{m}\left(871\right.$ and $\left.512 \mathrm{~cm}^{-1}\right)$ (see details in Barker 1963). Especially for $\gamma-\mathrm{Al}_{2} \mathrm{O}_{3}$, there exist vibrational frequencies in the range from 12.5 to $14.29 \mu \mathrm{m}\left(680-500 \mathrm{~cm}^{-1}\right)$ and from 14.71 to $20 \mu \mathrm{m}\left(800-700 \mathrm{~cm}^{-1}\right)$ (Saniger 1995).

Optical properties of various $\alpha-\mathrm{Al}_{2} \mathrm{O}_{3}$ samples have been analyzed by many groups (e.g. Barker 1963; Loewenstein et al. 1973; Querry 1985; Gervais 1991) as well as $\gamma-\mathrm{Al}_{2} \mathrm{O}_{3}$ (e.g. Chu et al. 1988; Koike et al. 1995), $\delta$ - and $\theta-\mathrm{Al}_{2} \mathrm{O}_{3}$ (Kurumada et al. 2005), and amorphous $\mathrm{Al}_{2} \mathrm{O}_{3}$ (e.g. Chu et al. 1988; Begemann et al. 1997).

\section{A.8. $\mathrm{MgAl}_{2} \mathrm{O}_{4}$}

$\mathrm{MgAl}_{2} \mathrm{O}_{4}$ (spinel) is known to be an important ferromagnetic material, which has very high permeability (e.g. Douglas \& Ho 2006) and a cubic close-packed anion arrangement (e.g. Rohrer 2001) like most metallic crystals. The general formula of the spinel group can be described as $\mathrm{XY}_{2} \mathrm{O}_{4}$. $\mathrm{X}$ would be replaced with $\mathrm{Mg}^{2+}, \mathrm{Fe}^{2+}, \mathrm{Ti}^{4+}, \mathrm{Zn}^{2+}$, or $\mathrm{Mn}^{2+}$. $\mathrm{Y}$ may be occupied by $\mathrm{Al}^{3+}, \mathrm{Fe}^{3+}, \mathrm{Fe}^{2+}$, or $\mathrm{Cr}^{3+}$.

In the case of magnesium aluminum spinel $\left(\mathrm{MgAl}_{2} \mathrm{O}_{4}\right)$, the oxygens form a face-centered cubic closed-packed array along planes in the structure. Then, $\mathrm{Mg}^{2+}$ ions are placed in tetrahedral interstices ( $1 / 8$ occupied) whereas $\mathrm{Al}^{3+}$ ions sit in octahedral (1/2 occupied) sites in the lattice. Eight tetrahedral sites are occupied by $\mathrm{Mg}^{2+}$ ions, and 16 octahedral sites are filled by $\mathrm{Al}^{3+}$ ions surrounded by $32 \mathrm{O}^{2-}$ ions in a unit cell of the spinel. In consequence, spinel has 56 ions per unit cell (see details in Klein \& Hurlbut 1993; Fabian et al. 2001).

Spinel can be found as a natural mineral and can also be syntheszed. $\mathrm{Mg}^{2+}$ and $\mathrm{Al}^{3+}$ ions are originally well ordered in natural spinel lattices; however, the spinel crystal undergoes disordering by annealing. Disordering of these cations is seen in both annealed and synthetic crystal spinels. The structural transition occurs at temperatures between 1023 and $1073 \mathrm{~K}$ due to the 
disordering (see details in Schmocker et al. 1972; Fabian et al. 2001). The melting point of spinel is $2408 \mathrm{~K}$ (Lide 1990).

Possible spinel formation pathways depend on temperature. At higher temperature, spinel grains may be formed via the reaction

$$
\mathrm{Mg}(\text { gas })+2 \mathrm{Al}(\text { gas })+4 \mathrm{O}(\text { gas }) \longrightarrow \mathrm{MgAl}_{2} \mathrm{O}_{4}(\text { solid }) \text {. }
$$

As the temperature drops around $1758 \mathrm{~K}, \mathrm{Al}$ is not able to remain in the gas phase together with three oxygens for every two atoms. Thus, it is conceivable that spinel forms via a chemical reaction with corundum at lower temperature $(\approx 1500 \mathrm{~K})$

$\mathrm{Mg}$ (gas) $+\mathrm{O}($ gas $)+\mathrm{Al}_{2} \mathrm{O}_{3}$ (cry) $\longrightarrow \mathrm{MgAl}_{2} \mathrm{O}_{4}$ (cry)

(“cry" denotes crystalline) (Grossman \& Larimer 1974).

In addition, spinel formation has been confirmed in shock induced experiments by making use of single crystals of corundum and periclase $(\mathrm{MgO})$ (Potter \& Ahrens 1994). They reported that a $\mathrm{MgAl}_{2} \mathrm{O}_{4}$ layer is formed at the boundary between these two crystals under particular conditions. Hence, it is also possible that spinel forms via a solid-solid reaction with some shock impacts

$$
\mathrm{MgO}\left(\text { cry) }+\mathrm{Al}_{2} \mathrm{O}_{3} \text { (cry) } \longrightarrow \mathrm{MgAl}_{2} \mathrm{O}_{4}\right. \text { (cry). }
$$

The fundamental (one photon) lattice vibrations of spinel generate bands between 12.5 and $33.3 \mu \mathrm{m}\left(800-300 \mathrm{~cm}^{-1}\right.$ ) (Tropf \& Thomas 1991).

Optical properties of $\mathrm{MgAl}_{2} \mathrm{O}_{4}$ have been investigated by e.g. Tropf \& Thomas (1991), Chihara et al. (2000), and Fabian et al. (2001). Chihara et al. (2000) and Fabian et al. (2001) derived the optical constants of both natural and synthetic spinels from reflectance measurements.

\section{References}

Allard, F., Hauschildt, P. H., Alexander, D. R., Tamanai, A., \& Schweitzer, A. 2001, ApJ, 556, 357

Åsbrink, S., \& Magnéli, A. 1959, Acta Cryst., 12, 575

Barker, A. S. Jr. 1963, Phys. Rev., 132, 1474

Begemann, B., Dorschner, J., Henning, Th., \& Mutschke, H. 1997, ApJ, 476, 199

Bhattacharya, I. N., Das, S. C., Mukherjee, P. S., Paul, S., \& Mitra, P. K. 2004, Scand. J. Metall., 33, 211

Blum, J., Wurm, G., Poppe, T., et al. 2000, Phys. Rev. Lett., 85, 2426

Brandes, E. A., \& Brook, G. B. 1992, Smithells Metal Reference Book (Oxford: Butterworth-Heinemann Ltd.)

Bohren, C. F., \& Huffman, D. R. 1983, Absorption and Scattering of Light by Small Particles (N.Y.: John Wiley \& Sons Inc.)

Buscaglia, V., Delfrate, M. A., Leoni, M., \& Bottino, C. 1996, J. Mater. Sci., 31, 1715

Cameron, A. G. W. 1973, Space Sci. Rev., 15, 121

Cami, J. 2002, Ph.D. Thesis, University of Amsterdam, The Netherlands

Chihara, H., Tsuchiyama, A., Koike, C., \& Sogawa, H. 2000, in Disks Planetesimals and Planets, ed. F. Garzon, C. Eiroa, D. de Winter, \& T. J. Mahoney, ASP Conf. Ser., 219, 150

Chihara, H., Koike, C., Tsuchiyama, A., Tachibana, S., \& Sakamoto, D. 2002, A\&A, 391, 267

Chu, Y. T., Bates, J. B., White, C. W., \& Farlow, G. C. 1988, J. Appl. Phys., 64, 3727

Clément, D., Mutschke, H., Klein, R., \& Henning, Th. 2003, ApJ, 594, 642

Coelho, A. C. V., Santos, H. de S., Kiyohara, P. K., Marcos, K. N. P., \& Santos, P. de S. 2007, Matar. Res., 10, 183

DePew, K., Speck, A., \& Dijkstra, C. 2006, ApJ, 640, 971

Draine, B. T. 1988, ApJ, 333, 848

Dorschner, J., Friedemann, C., \& Gürtler, J. 1978, Astron. Nachr., 299, 6

Douglas, B. E., \& Ho, S. M. 2006, Structure and Chemistry of Crystalline Solids (N.Y.: Springer)

Fabian, D., Posch, Th., Mutschke, H., Kerschbaum, F., \& Dorschner 2001, A\&A, 373, 1125

Ferguson, J. W., Alexander, D. R., Allard, F., et al. 2005, ApJ, 623, 585
Ferrarotti, A. S., \& Gail, H.-P. 2001, A\&A, 371, 133

Freundenberg, B., \& Mocellin, A. 1987, J. Am. Ceram. Soc., 70, 33

Freundenberg, B., \& Mocellin, A. 1988, J. Am. Ceram. Soc., 71, 22

Fujimura, T., Iwasaki, H., Kkegawa, T., et al. 1989, High Pressure Research, 1, 213

Gail, H. P., \& Sedlmayr, E. 1998, Faraday Discuss., 109, 303

Gail, H. P., \& Sedlmayr, E. 1999, A\&A, 347, 594

Gervais, F. 1991, Handbook of Optical Constants of Solids II, ed. E. D. Palik (Orland: Academic Press Inc.), 1035

Gillet, P., Guyot, F., Price, G. D., Tournerie, B., \& Le Cleach, A. 1993, Phys. Chem. Minerals, 20, 1993

Gusev, A. I. 1991, Phys. Stat. Sol. (b), 163, 17

Glaccum, W. 1995, in Proc. Airborne Astronomy Haas, ed. J. A. Davidson, \& E. F. Erickson (San Francisco: ASP), ASP Conf. Proc., 73, 395

Greshake, A., Bischoff, A., \& Putnis, A. 1996, Lunar \& Planetary Science, 27, 463

Greshake, A., Bischoff, A., \& Putnis, A. 1998, Meteoritics \& Planetary Science, 33,75

Grossman, L., \& Larimer, J. W. 1974, Rev. Geophys. Space Phys., 12, 71

Habing, H. J., \& Olofsson, H. 2004, Asymptotic Giant Branch Stars, ed. H. J. Habing, \& H. Olofsson (N.Y.: Springer-Verlag), 1

Henning, Th., \& Mutschke, H. 2000, in Thermal Emission Spectroscopy and Analysis of Dust, Disks, and Regoliths, ed. M. L. Sitko, A. L. Sprague, \& D. K. Lynch, 196, 253

Hinds, W. C. 1999, Aerosol Technology: Properties, Behavior, and Measurement of Airborne Particles (N.Y.: John Wiley \& Sons Inc.)

International Advanced Materials 1999, http://www.iamaterials.com/ compounds/titaniumoxide4.htm

Jäger, C., Mutschke, H., Begemann, B., Dorschner, J., \& Henning, Th. 1994, A\&A, 292, 641

Jäger, C., Dorschner, J., Mutschke, H., Posch, Th., \& Henning, Th. 2003, A\&A, 408, 193

Jeong, K. S., Winters, J. M., \& Sedlmayr, E. 1999, in Asymptotic Giant Branch Stars, ed. T. LeBerte, A. Lebre, \& C. Waelkens, IAU Symp., 191, 233

Jianu, A., Stanciu, L., Groza, J. R., Lathe, Ch., \& Burkel, E. 2003, Nucl. Instrum. Methods B, 199, 44

Jun, S. G., Bursill, L. A., Yoshida, K., Yamada, Y., \& Ota, H. 1984, Acta Cryst., B40, 549

Klein, C., \& Hurlbut, C. S. Jr. 1993, Manual of Mineralogy (N.Y.: John Wiley \& Sons, Inc.)

Koike, C., Hasegawa, H., Asada, N., \& Hattori, T. 1981, Ap\&SS, 79, 77

Koike, C., \& Hasegawa, H. 1987, Ap\&SS, 134, 361

Koike, C., Kaito, C., Yamamoto, T., et al. 1995, Icarus, 114, 203

Kozasa, T., \& Sogawa, H. 1997, Ap\&SS, 255, 437

Krause, M., \& Blum, J. 2004, Phys. Rev. Lett., 93, 021103

Kurumada, M., Koike, C., \& Kaito, C. 2005, MNRAS, 359, 643

Lide, D. R. 1990, CRC Handbook of Chemistry and Physics (Boston: CRC Press Inc.)

Linsebigler, A. L., Lu, G., \& Yated, J. T. Jr. 1995, Chem. Rev., 95, 735

Loewenstein, E. V., Smith, D. R., \& Morgan, R. L. 1973, Applied Optics, 12, 398

Lucovsky, G., Sladek, R. J., \& Allen, J. W. 1977, Phys. Rev. B, 16, 5452

Mackowski, D. W., \& Mishchenko, M. I. 1996, J. Opt. Soc. Am. A, 13, 2266

Mie, G. 1908, Ann. Phys., 25, 377

Millar, T. J. 2004, Asymptotic Giant Branch Stars, ed. H. J. Habing, \& H. Olofsson (N.Y.: Springer-Verlag), 247

Min, M., Hovenier, J. W., de Koter, A., Waters, L. B. F. M., \& Dominik, C. 2005, Icarus, 179,158

Min, M., Hovenier, J. W., Dominik, C., de Koter, A., \& Yurkin, M. A. 2006, J. Quant. Spec. Radiat. Transf., 97, 161

Mishchenko, M. I. 1990, Ap\&SS, 164, 1

Mo, S.-D., \& Ching, W. Y. 1995, Phys. Rev. B, 51, 13023

Muraishi, H. 2004, Basic Solid State Chemistry for Inorganic Materials (Tokyo: Sankyo Shuppan Inc.)

Nittler, L. R., Alexander, C. M. O’D., Stadermann, F. J., \& Zinner, E. K. 2005, in 36th Annual Lunar and Planetary Science Conference, Abst. No. 2200

Nittler, L. R., Alexander, C. M. O’D., Gallino, R., et al. 2008, ApJ, 686, 1524

Onaka, T., de Jong, T., \& Willems, F. J. 1989, A\&A, 218, 169

Onoda, M. 1998, J. Solid State Chem., 136, 67

Orofino, V., Blanco, A., Mennella, V., et al. 1991, A\&A, 252, 315

Ossenkopf, V., Henning, Th., \& Mathis, J. S. 1992, A\&A, 261, 567

Papoular, R., Cauchetier, M., Begin, S., \& LeCaer, G. 1998, A\&A, 329, 1035

Paszun, D., \& Dominik, C. 2006, Icarus, 182, 274

Perry, C. H., \& Khanna, B. N. 1964, Phys. Rev. A, 135, 408

Posch, Th., Kerschbaum, F., Mutschke, H., et al. 1999, A\&A, 352, 609

Posch, Th., Kerschbaum, F., Mutschke, H., Dorschner, J., \& Jäger, C. 2002, A\&A, 393, L7

Posch, Th., Kerschbaum, F., Fabian, D., et al. 2003, ApJS, 149, 437 
Potter, D. K., \& Ahrens, T. J. 1994, Geophys. Res. Lett., 21, 721

Preudhomme, J., \& Tarte, P. 1971, Spectrochimica Acta, 27A, 961

Purcell, E. M., \& Pennypacker, C. R. 1973, ApJ, 186, 705

Querry, M. R. 1985, Optical Constants (Maryland: Chemical Research and Development Center)

Reade Advanced Materials 1997, http://www.reade.com/Products/ Minerals_and_Ores/anatase.html

Redfern, S. A. T., \& Carpenter, M. A. 2000, Transformation Processes in Minerals (Washington DC: Mineralogical Society of America)

Ribarsky, M. W. 1985, Handbook of Optical Constants of Solids, ed. E. D. Palik (Orland: Academic Press Inc.), 795

Rohrer, G. S. 2001, Structure and bonding in crystalline materials (Cambridge: Cambridge Univ. Press)

Saalfeld, H. 1958, Clay Min. Bull., 3, 249

Saniger, J. M. 1995, Materials Lett., 22, 109

Santos, P. S., Santos, H. S., \& Toledo, S. P. 2000, Mater. Res., 3, 104

Schmocker, U., Boesch, H. R., \& Waldner, F. 1972, Phys. Lett., 40A, 237

Sedlmayr, E. 1994, in Molecules in the Stellar Environment, ed. U. G. Jorgensen (Berlin: Springer-Verlag), 428, 163

Sharp, C. M., \& Huebner, W. F. 1990, ApJS, 72, 417

Sloan, G. C., Kraemer, K. E., Goebel, J. H., \& Price, S. D. 2003, ApJ, 594, 483
Speck, A. K., Barlow, M. J., Sylvester, R. J., \& Hofmeister, A. M. 2000, A\&AS, 146,437

Stanciu, L. A., Groza, J. R., Jitianu, A., \& Zaharescu, M. 2004, Mater. Manuf. Process, 19, 641

Straumanis, M. E., \& Ejima, T. 1962, Acta Cryst., 15, 404

Streitz, F. H., \& Mintmire, J. W. 1999, Phys. Rev. B, 60, 773

Stroud, R. M., Nittler, L. R., \& Alexander, C. M. O'D. 2004, Science, 305, 1455

Tamanai, A., Mutschke, H., Blum, J., Neuhäuser, R. 2006a, J. Quant. Spec. Radiat. Transf., 100, 373

Tamanai, A., Mutschke, H., Blum, J., \& Meeus, G. 2006b, ApJ, 648, L147 Tamanai, A. 2007, Ph.D. Thesis, FSU Jena, Germany

Tropf, W. J., \& Thomas, M. E. 1991, Handbook of Optical Constants of Solids II, ed. E. D. Palik (Orland: Academic Press Inc.), 883

Wefers, K., \& Misra, C. 1987, Oxides and Hydroxides of Aluminum (USA: Alcoa Research Laboratories)

Wells, A. F. 1991, Structural Inorganic Chemistry (Oxford: Clarendon Press)

Woignier, T., Lespade, P., Phalippou, J., \& Rogier R. 1988, J. Non-Cryst. Solids, 100,325

Zebel, G. 1966, Coagulation of Aerosols, in Aerosol Science, ed. C. N. Davis (N.Y.: Academic Press), 31

Zribi, M., Kanzari, M., \& Rezig, B. 2008, Thin Solid Films, 516, 1476 